\title{
WestVirginiaUniversity
}

THE RESEARCH REPOSITORY @ WVU

Graduate Theses, Dissertations, and Problem Reports

2005

\section{Energy-sensitive machining parameter optimization model}

\author{
Deepak Prakash Gupta
}

West Virginia University

Follow this and additional works at: https://researchrepository.wvu.edu/etd

\section{Recommended Citation}

Gupta, Deepak Prakash, "Energy-sensitive machining parameter optimization model" (2005). Graduate Theses, Dissertations, and Problem Reports. 4152.

https://researchrepository.wvu.edu/etd/4152

This Thesis is protected by copyright and/or related rights. It has been brought to you by the The Research Repository @ WVU with permission from the rights-holder(s). You are free to use this Thesis in any way that is permitted by the copyright and related rights legislation that applies to your use. For other uses you must obtain permission from the rights-holder(s) directly, unless additional rights are indicated by a Creative Commons license in the record and/ or on the work itself. This Thesis has been accepted for inclusion in WVU Graduate Theses, Dissertations, and Problem Reports collection by an authorized administrator of The Research Repository @ WVU. For more information, please contact researchrepository@mail.wvu.edu. 
Energy Sensitive Machining Parameter Optimization Model

\author{
Deepak Prakash Gupta
}

\author{
Thesis submitted to the \\ College of Engineering and Mineral Resources \\ at West Virginia University \\ in partial fulfillment of the requirements \\ for the degree of \\ Master of Science \\ in \\ Industrial Engineering
}

B. Gopalakrishnan, Ph.D., Chair

Wafik H. Iskander, Ph.D.

Robert C. Creese, Ph.D.

Department of Industrial and Management Systems Engineering Morgantown, West Virginia

2005

Keywords: Machining, Turning, Energy, Geometric Programming 


\section{Abstract \\ Energy Sensitive Machining Parameter Optimization Model \\ Deepak Prakash Gupta}

Manufacturing industries are one of the most important elements in the economic growth and stability of any country. It is very important that the process parameters are given proper attention to maximize the value addition and increased profits for these industries. Parameter optimization for different manufacturing processes has been a challenging and interesting problem in the past. Many researchers have studied the problem of optimizing the process parameters for the turning process. In all the cases studied so far, no one has considered the significance of energy required and its cost for the machining process as an integral part of the optimization process. With the recent problems in the supply of energy and the increasing energy demand and cost, consideration of issues and problems related to energy usage has become a priority for the manufacturing industry.

The proposed research aims to bridge the gap between the concept of machining economics and the energy conservation. A single pass turning operation was considered, to demonstrate the optimization of process parameters so that the overall cost of manufacturing is minimized. A geometric programming mathematical model was developed to address the concept of energy sensitive parameter optimization process. The proposed model adds a new dimension to the existing literature on machining economics problems since the energy cost has never been considered in the optimization process. A solution methodology had been developed to find the optimal or near optimal process parameters. Last but not the least; this research is focused on today's need of the world, the energy efficiency awareness. 


\section{Acknowledgement}

I would like to thank Dr. Gopalakrishnan for his constant advice and support as my research advisor throughout this research work. I would also like to thank Dr. Iskander and Dr. Creese, my committee members, for their invaluable suggestions for improvements during my research.

I am grateful to my parents and my brother and sisters for their continued moral support. It was impossible to stay this far from them and do this work without their confidence in me.

I also like to thank Dr. J.L. Gandhar and Dr. Pradeep Kumar (at IIT, Roorkee, India) for the encouragement I received from them to come to the United States and achieve this success thereafter.

Last but not the least, I am thankful to all my friends for the moments I shared with them and pray God to make them achieve all the success in their lives. 


\section{Table of Contents}

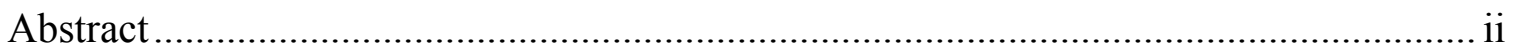

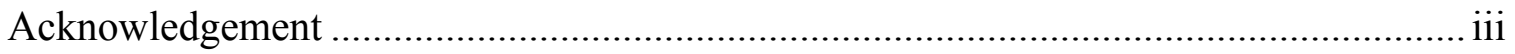

List of Tables ................................................................................................. vi

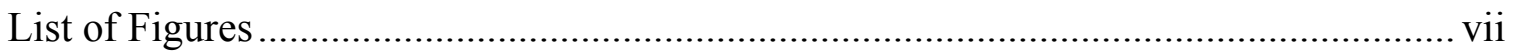

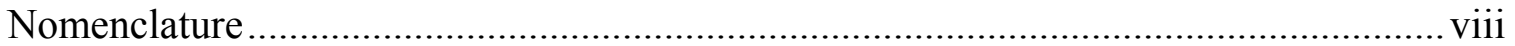

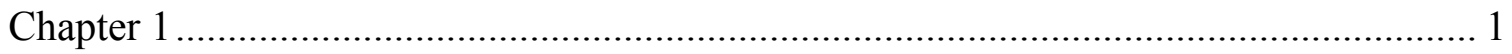

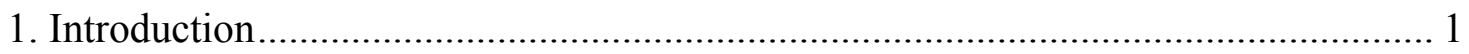

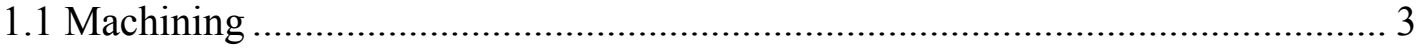

1.1.1 Turning Process .................................................................................. 4

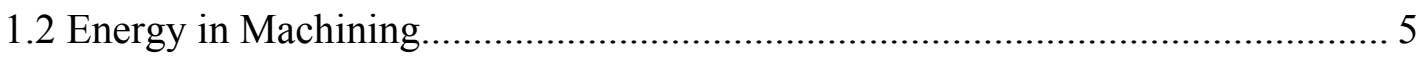

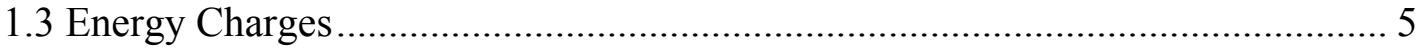

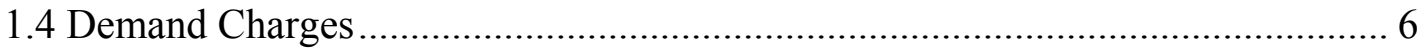

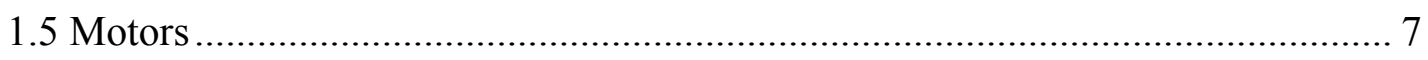

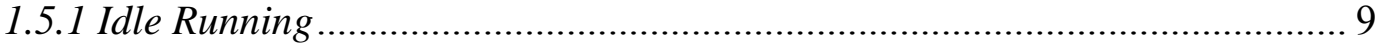

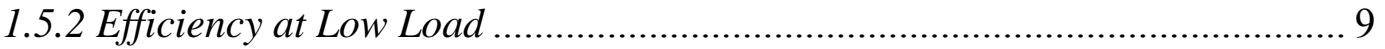

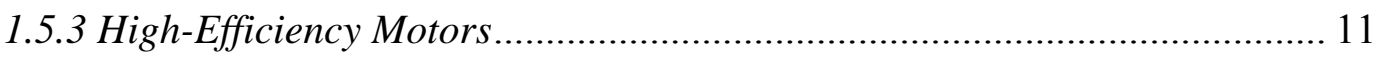

1.6 Impact of Energy Cost on Profitability ...................................................... 11

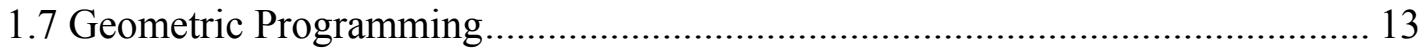

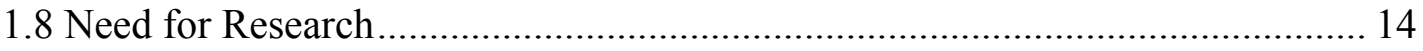

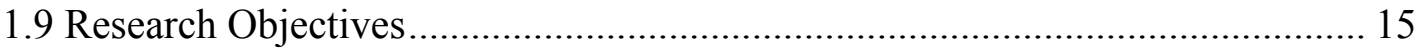

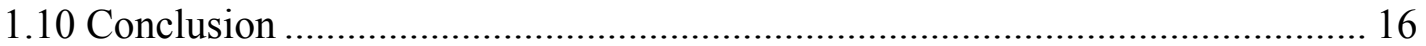

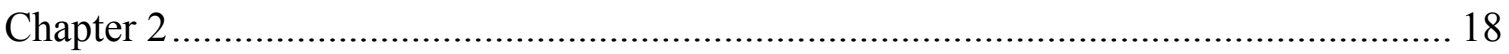

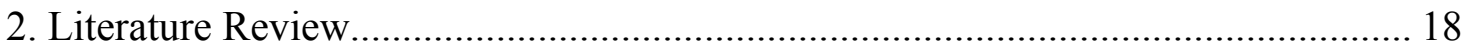

2.1 Machining Cost and/or Time Models ...................................................... 18

2.2 Energy Consumption Models .................................................................... 23

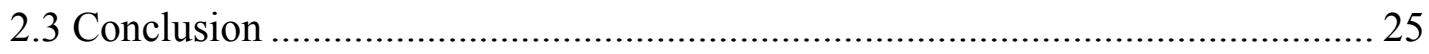

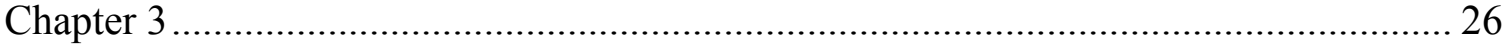

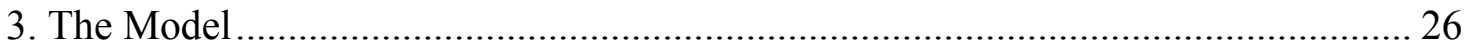

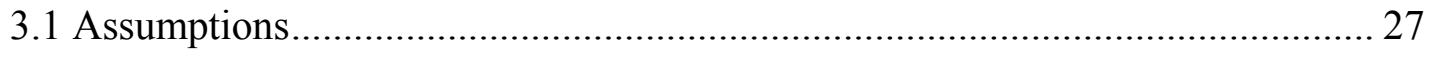




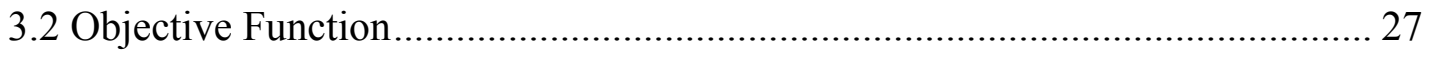

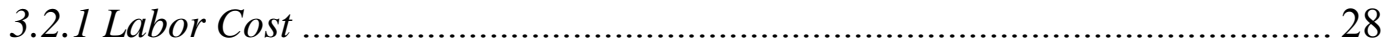

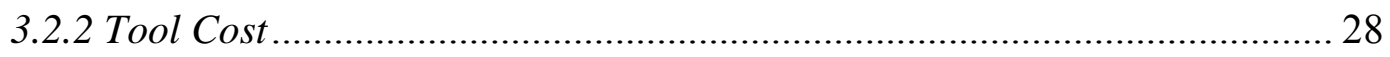

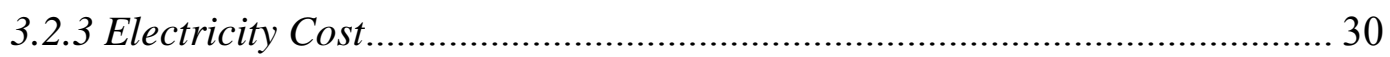

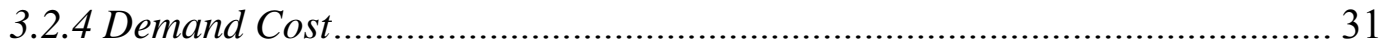

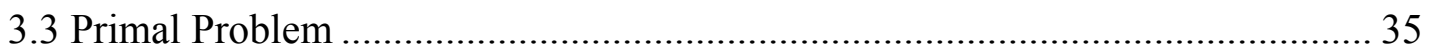

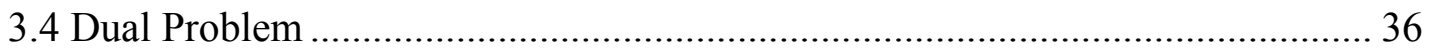

3.5 Derivation of Primal Solution from Dual Solution............................................. 41

3.6 Computer Model Development....................................................................... 42

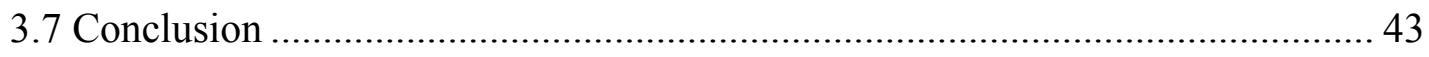

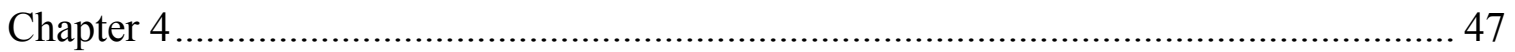

4. Model Validation and Sensitivity Analysis .......................................................... 47

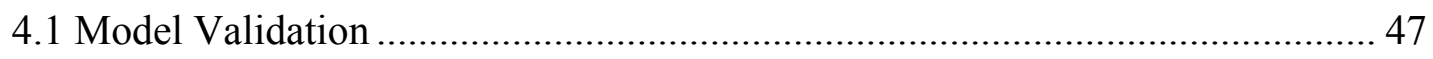

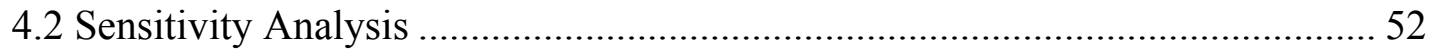

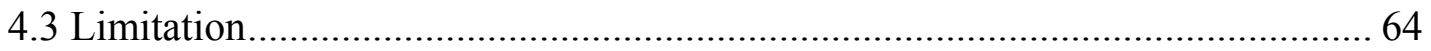

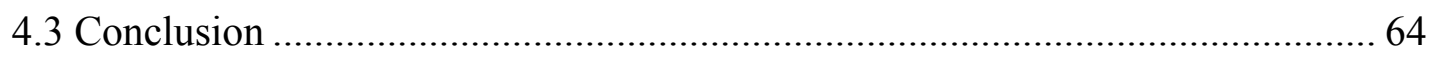

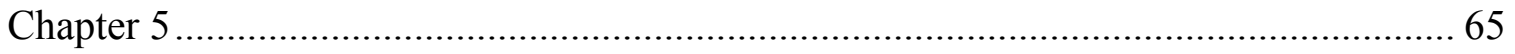

5. Conclusion and Future Research Work ................................................................. 65

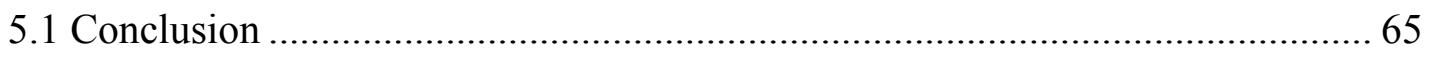

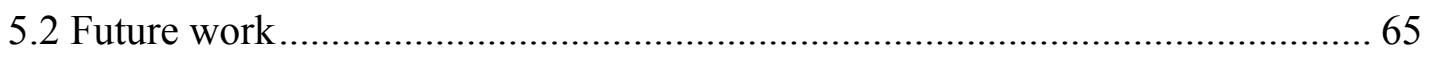

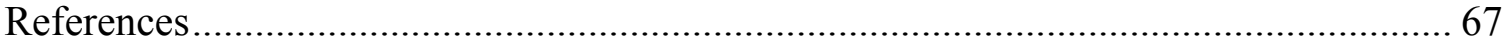




\section{List of Tables}

Table 1.1: Example demand for a 15-minute interval ........................................... 7

Table 1.2: Example companies and their net profit margin......................................... 12

Table 3.1: Proposed correction factor for demand cost calculations ............................. 32 


\section{List of Figures}

Figure 1.1: Production and consumption of energy in the U.S...................................... 2

Figure 1.2: Turning process .................................................................................. 4

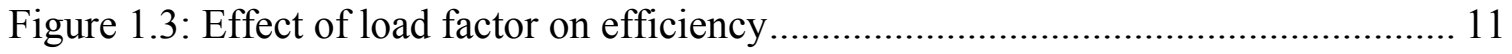

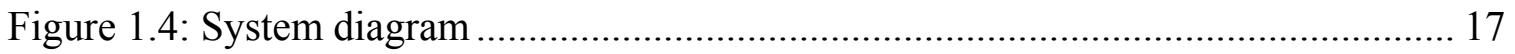

Figure 3.1: Plot of dual objective function value vs. dual variable value....................... 40

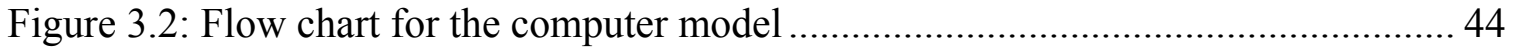

Figure 3.3: Input module for the computer model ................................................. 45

Figure 3.4: Results module for the computer model................................................. 46

Figure 4.1: Effect of labor rate on percentage cost savings ....................................... 52

Figure 4.2: Effect of labor rate on percentage time savings ........................................ 53

Figure 4.3: Effect of tool constant on percentage cost savings................................... 54

Figure 4.4: Effect of tool constant on percentage time savings ................................... 54

Figure 4.5: Effect of unit demand cost on percentage cost savings ..............................55

Figure 4.6: Effect of unit demand cost on percentage time savings ............................. 55

Figure 4.7: Effect of energy usage rate on percentage cost savings ..............................56

Figure 4.8: Effect of energy usage rate on percentage time savings ............................. 57

Figure 4.9: Effect of required surface finish on percentage cost savings ...................... 57

Figure 4.10: Effect of required surface finish on percentage time savings .................... 58

Figure 4.11: Effect of tool cost/edge on percentage cost savings ................................ 59

Figure 4.12: Effect of tool cost/edge on percentage time savings ................................59

Figure 4.13: Effect of energy usage and demand rate on percentage cost savings........... 60

Figure 4.14: Effect of energy usage and demand rate on percentage time savings .......... 60

Figure 4.15: Effect of demand and labor rate on percentage time savings..................... 61

Figure 4.16: Effect of energy usage and labor rate on percentage time savings ............. 62

Figure 4.17: Effect of energy usage rate on percentage energy savings ......................... 63

Figure 4.18: Effect of demand rate on percentage energy savings ............................... 64 


\section{Nomenclature}

$\mathrm{b}, \mathrm{c}, \mathrm{e}=$ Exponents in the machine power constraints

$\mathrm{C}=$ Constant in Taylor's tool life equation

$\mathrm{C}_{1} \quad=$ Coefficient of labor cost term in the objective function

$\mathrm{C}_{2} \quad=$ Coefficient of tool related cost term in the objective function

$\mathrm{C}_{3} \quad=$ Coefficient of energy related cost term in the objective function

$\mathrm{C}_{\mathrm{ijk}} \quad=$ Constants in the dual problem equations

$C_{k W / H P}=$ Conversion factor from horsepower to kilowatt, $0.746 \mathrm{~kW} / \mathrm{HP}$

$C_{L} \quad=$ Constant in the equation for energy usage cost component

$C_{M} \quad=$ Constant in the equation for demand cost component

$\mathrm{C}_{\mathrm{m}}{ }^{\prime} \quad=$ Coefficient in machine power constraint, $\left(\mathrm{C}_{\mathrm{m}}{ }^{*} \mathrm{~d}^{\mathrm{e}}\right)$

$\mathrm{C}_{\mathrm{s}} \quad=$ Coefficient in surface finish constraint in the literature

$\mathrm{C}_{\mathrm{s}}{ }^{\prime} \quad=$ Coefficient in the standardized surface finish constraint, $\left(\mathrm{C}_{\mathrm{s}}{ }^{*} \mathrm{~d}^{\mathrm{i}}\right)$

$\mathrm{C}_{\mathrm{u}} \quad=$ Unit cost of machining in the primal problem, \$/unit

$\mathrm{CF} \quad=$ Correction factor for demand cost calculations

$\mathrm{d}=$ Depth of cut, inches

D $=$ Diameter of the workpiece, inches

$\mathrm{DC}=$ Demand cost, $\$$

DT = Demand peak during rapid traverse, $\mathrm{kW}$

$\mathrm{DR}=$ Demand rate, $\$ \mathrm{~kW}$

$\mathrm{DU}=$ Energy demand during machining, $\mathrm{kW}$

EC = Energy usage cost, $\$$

ER = Energy usage rate, $\$ / \mathrm{kWh}$

$\mathrm{EU} \quad=$ Energy usage for the turning process, $\mathrm{kWh}$

f $\quad=$ Cutting feed, inches/rev or i.p.r.

$\mathrm{g}, \mathrm{h}, \mathrm{i}=$ Exponents in surface finish constraints

$\mathrm{HP}_{\max }=$ Maximum machine power available, $\mathrm{HP}$

$1=$ Length of workpiece, inches

$\mathrm{L}_{\mathrm{r}} \quad=$ Labor cost per unit time, $\$ /$ minute

$\mathrm{LC}=$ Labor cost, $\$$

$\mathrm{LF} \quad=$ Motor load factor 


$$
\begin{aligned}
& \mathrm{N} \quad=\text { Rotational speed, } \mathrm{rpm} \\
& \mathrm{n}, \mathrm{m}, \mathrm{p}=\text { Exponents in extended Taylor's tool life equation } \\
& n_{u} \quad=\text { Number of units to share the demand cost } \\
& \mathrm{SF}_{\max }=\text { Maximum acceptable surface finish, inches } \\
& T_{c} \quad=\text { Time to change a tool, minutes } \\
& T_{\text {cost }}=\text { Cost of tool per edge, \$/edge } \\
& \mathrm{T}_{\mathrm{m}} \quad=\text { Time of machining, minutes } \\
& \text { TC }=\text { Cost related to tool, } \$ \\
& \mathrm{~V}=\text { Cutting Speed, feet/minute or surface feet/min (sfpm) } \\
& \mathrm{W}_{\mathrm{i}}=\mathrm{i}^{\text {th }} \text { dual variable } \\
& \mathrm{Z} \quad=\text { Dual objective function variable } \\
& \eta \quad=\text { Efficiency of the motor }
\end{aligned}
$$

The following are applicable only to the dual programming formulation in Section 1.7

$$
\begin{array}{ll}
\mathrm{a}_{\mathrm{im}} & =\text { Exponent for the } \mathrm{m}^{\text {th }} \text { primal variable in the } \mathrm{i}^{\text {th }} \text { term } \\
\mathrm{C}_{\mathrm{i}} & =\text { Constant in the } \mathrm{i}^{\text {th }} \text { term } \\
\mathrm{g}_{\mathrm{k}}(\mathrm{t}) \quad=\mathrm{k}^{\text {th }} \text { constraint function } \forall \mathrm{k}=1,2, \ldots, \mathrm{p} \\
\mathrm{g}_{0}(\mathrm{t}) \quad=\text { Objective function } \\
\mathrm{i} \\
\mathrm{J}[\mathrm{k}] \quad=\text { An element from } \mathrm{J}[\mathrm{k}]
\end{array}
$$$$
\text { and } \mathrm{k}=1,2, \ldots, \mathrm{p} \text { for the constraints }
$$$$
\mathrm{m}=\text { Number of primal variables }
$$$$
\mathrm{n} \quad=\text { Total number of terms in the primal problem }
$$$$
\mathrm{n}_{0} \quad=\text { Number of terms in the objective function }
$$$$
\mathrm{n}_{\mathrm{k}} \quad=\text { Total number of terms in till } \mathrm{k}^{\text {th }} \text { constraint including } \mathrm{n}_{0}
$$$$
\mathrm{p} \quad=\text { Number of constraints }
$$$$
\mathrm{t}_{\mathrm{m}} \quad=\mathrm{m}^{\text {th }} \text { primal variable }
$$$$
\mathrm{v}(\delta)=\text { Dual objective function }
$$$$
\delta_{\mathrm{i}} \quad=\text { Dual variable associate with the } \mathrm{i}^{\text {th }} \text { terms in the primal formulation }
$$$$
\lambda_{\mathrm{k}}(\delta)=\text { Sum of dual variable related to the terms in } \mathrm{k}^{\text {th }} \text { constraint } \forall \mathrm{k}=1,2, \ldots, \mathrm{p}
$$ 


\section{Chapter 1}

\section{Introduction}

Due to high levels of automation and market pressure to reduce the high operating and capital costs, it is estimated that modern manufacturing systems would use as high as $80 \%$ of the available production time on machining as compared to $5 \%$ in conventional machining [Merchant, 1974]. Therefore, the savings through parameter optimization during actual machining may now be significant as more units are being produced with the same machine. This trend encourages the optimization of machining processes to increase the economic gains and to improve the processes which then will help the industry to be there in the market under current fierce competition. In the past, many researchers have worked on the problem of machining economics for different processes and developed numerous mathematical models. It had been an interesting problem for the researchers in the operations research group because of the complexity involved in the machining parameter modeling.

Manufacturing reduced to its simplest form, involves the controlled application of energy to convert raw material into finished products with definite shape, structure and properties [NRC, 1995]. It may be noted that energy has always been considered as an integral part of the manufacturing process but the sad part is that it has not been given proper attention in the past for machining parameter optimization. The reason may have been the low contribution towards the total cost during that time and the high profit margins in the business. But looking at the reducing supply and increasing demand of energy, it is most important to consider energy as an integral part in each and every aspect of machining parameter optimization process.

In the United States, manufacturing companies consume significant amount of energy with respect to other sectors and thus contribute to more environmental problems from the emissions. And today, not only the people from industry but the U.S. government is also concerned about reducing the energy consumption. One of the main reasons is that 
the demand for energy is increasing almost every day while the production is not able to keep up with the demands. Figure 1.1 presents the pattern of energy production and consumption from year 1949 through 2004 [EIA report, 2005]. It is apparent that the easiest way to satisfy the demand with almost constant rate of energy production is to make the processes more efficient and reduce the energy consumption wherever possible. In a letter [Executive Order 13123] dated June 8, 1999 from the White House, its was stated that "The Federal Government, as the Nation's largest energy consumer, shall significantly improve its energy management in order to save taxpayer dollars and reduce emissions that contribute to air pollution and global climate change." In the same report, in Section 201, it was stated that each agency under federal government should reduce its greenhouse gas emissions attributed to facility energy use by 30 percent by 2010 , compared to such emissions levels in 1990. Also, the industrial and laboratory facilities were asked to reduce energy consumption per square foot, per unit of production, or per other unit as applicable by 20 percent by 2005 and 25 percent by 2010 relative to 1990 [Executive Order 13123, 1999].

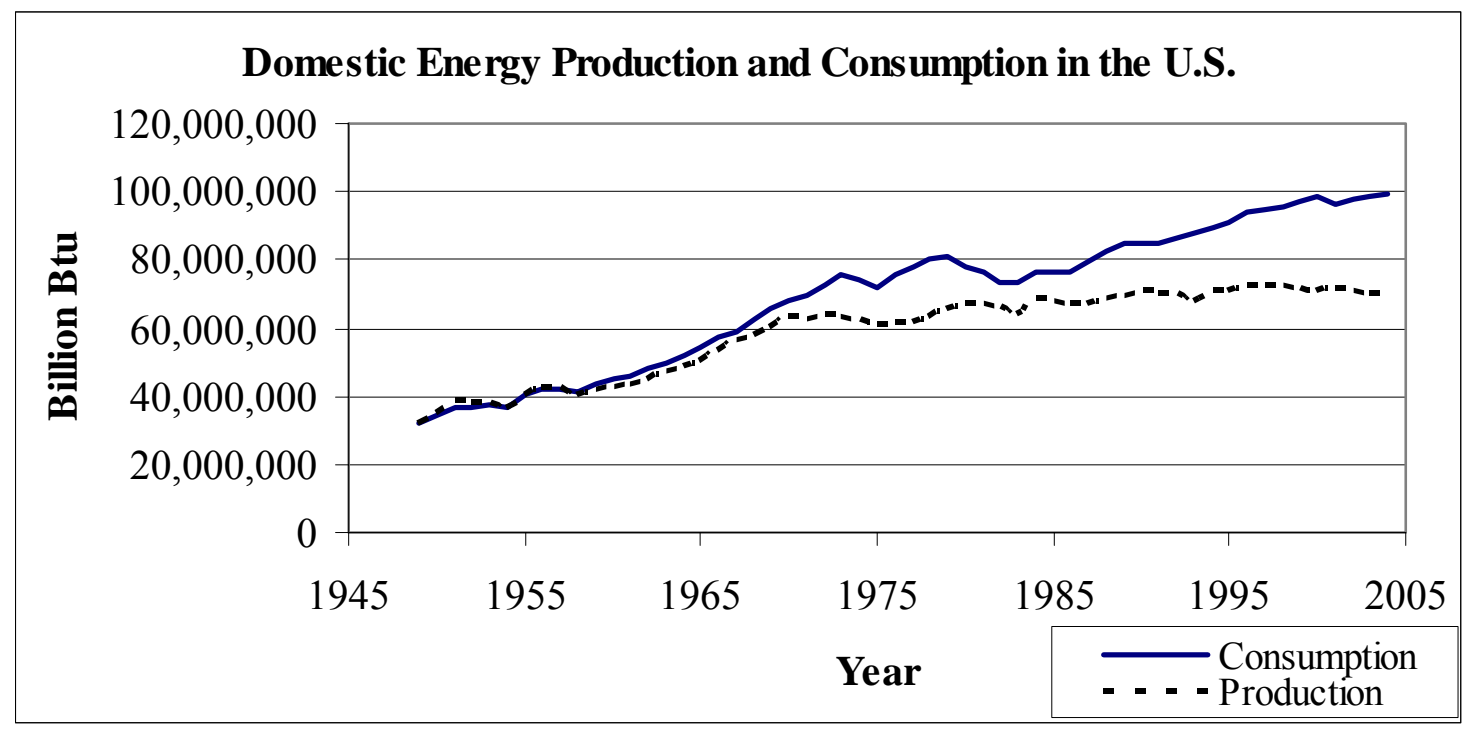

Figure 1.1: Production and consumption of energy in the U.S. [EIA report, 2005]

Apart from the internal reduction, different programs are also supported by the U.S. Department of Energy (DOE), e.g. Industrial Assessment Centers (IAC) and Industries of the Future (IOF) programs. Today, the world is concerned with utilizing the energy in the 
most efficient way. If proper attention to the energy usage is not given, the day is not far way when industry will not have sufficient energy to run their equipment, even with their best process parameter models. With this in mind, the current work is an attempt to increase the awareness in the manufacturing industries for the energy conservation opportunities. More specifically, this thesis is trying to incorporate the energy efficiency considerations into the machining economics models developed so far.

\subsection{Machining}

Machining is a major manufacturing process that plays an important role in the development of different products. Machining processes are differentiated on the basis of the nature of cutting with respect to the movement of the workpiece and cutting tool. Machining processes have been categorized in two main categories.

$>$ Traditional machining processes and

Non-traditional machining processes

Various traditional machining processes are turning, milling, shaping, grinding, drilling, boring, tapping, reaming, sawing, broaching, planning, filing, honing and facing etc. Non-traditional manufacturing processes include electro-discharge machining, water/abrasive jet machining, plasma beam machining, laser-beam machining, electron beam machining, chemical machining, ultrasonic machining, electrochemical machining, and micro machining, etc. Out of all the manufacturing processes, turning is one of the most widely used manufacturing processes in manufacturing industries. In fact, turning has been the preferred choice for most of the operations research group for development and analysis of the machining economics models. The following sections will briefly outline the turning process and the importance of parameter optimization for machining economics. 


\subsubsection{Turning Process}

Turning is typically performed on an axi-symmetrical product rotating about its axis. A cutting tool is fed against its surface radially at a certain depth of cut to remove the material and get the desired shape (Figure 1.2). Cutting parameters such as speed, feed rate and depth of cut affect the production rate and cost of the product for the turning process. The depth of cut is usually predetermined mainly by the size of work material and the product [Hitomi, 1996], and is fixed for a single pass turning operation. Therefore, cutting speed and feed rate are the main variables that determine the cost of product being manufactured.

Decisions regarding the process parameters are typically carried out by process planners or some machinist on the basis of their hands-on experience or with the help of some machining handbook. The restrictions that govern this decision are primarily the desired surface finish or other quality-related requirements and the demand. The selection of efficient process parameters has a direct impact on the production economics. Since the turning operation is a representative of machining processes, a single-pass turning process will be used to develop the machining economics model for machining processes in the manufacturing industries. The same concept can be extended to develop models for multi-pass turning operation or other processes as well.

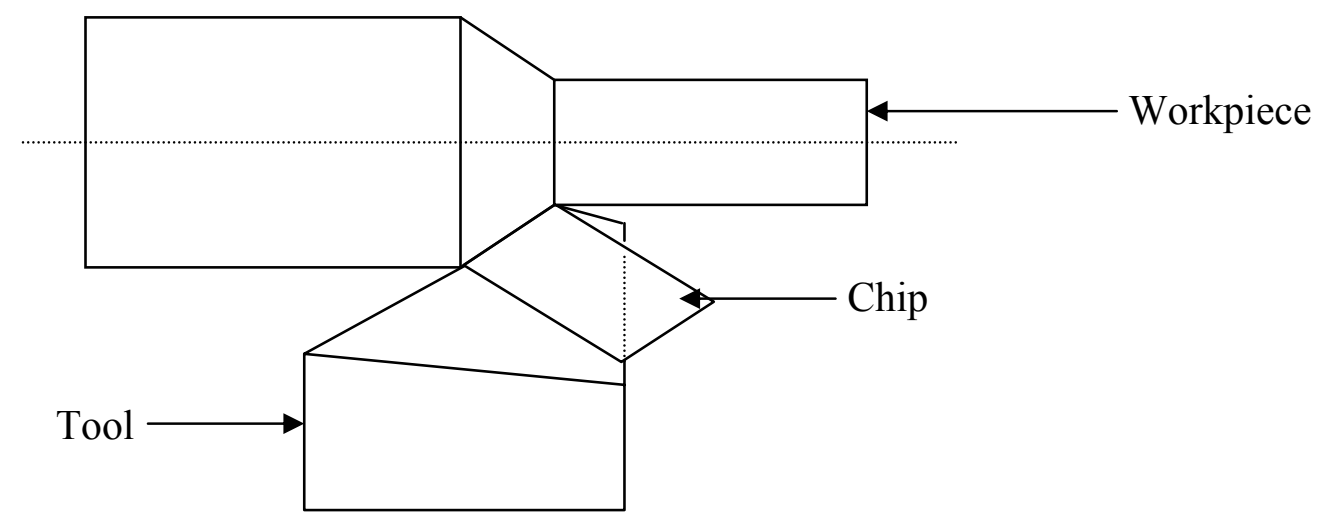

Figure 1.2: Turning process 


\subsection{Energy in Machining}

To perform the machining process, energy is required to run the machines e.g. lathe, CNC, etc. The required energy cost mainly has three components [Will, 1993]:

1. Fixed cost (consumer/customer charges, administrative costs); $\$ /$ month

2. Electricity cost i.e. the real cost of electricity that is consumed by the process (Variable costs); $\$ / \mathrm{kWh}$, and

3. Demand cost i.e. the cost of maintaining a level of energy to run the operation (investment costs); $\$ / \mathrm{kW}$

Out of these three components, the fixed cost (consumer/customer charges, administrative costs) has no direct relation to the turning process being considered. This cost is to cover the expenses in readings, accounting and billing by the power supplier company which is fixed each month. In general, this cost component is insignificant in comparison with the energy and demand charges and for the present analysis; it has not been included. The electricity and the demand cost are considered as the main energy cost components for the selection of optimal parameters for the turning operation.

The energy cost is based on the time spent to complete the machining operation, power $(\mathrm{kW})$ used for the machine, and unit cost of electricity $(\$ / \mathrm{kWHr})$ and demand $(\$ / \mathrm{kW})$. The details about these cost components are discussed in the following sections.

\subsection{Energy Charges}

Energy charge is based on the direct consumption of the electricity in terms of $\mathrm{kWh}$ (kilowatt hours) during the electricity consumption period. The $\mathrm{kWh}$ value is multiplied by the energy charges per unit for the total bill in the billing cycle. These charges may vary based on the service provider, voltage, and energy consumption during each billing cycle [Industrial Rates, 2005; Schedule 20, 2005; Schedule “B”, 2005; Schedule "C", 2005; Schedule “K”, 2005; Schedule 20, 2005]. 
Some of the examples for energy charges can be listed as follows.

1. A flat rate for each $\mathrm{kWh}$ consumed by the facility.

2. A variable rate based on the time of the day during which the electricity is consumed.

3. A variable rate based on the time of the year during which the electricity is consumed.

4. A flat or variable rate with low power factor penalty etc.

5. A flat or variable rate based on the total amount of power (kVA or $\mathrm{kW}$ ) consumed.

\subsection{Demand Charges}

This charge is to compensate the utility company for the capital investment required to serve peak loads, even if that peak load is only used for partial operating period. The demand is measured in $\mathrm{kW}$ (kilowatts) or kVA (kilovolt amperes). These units are related to the energy $(\mathrm{kWh})$ consumed in a given time interval of the billing period. The demand periods vary with the type of energy demand; the high fluctuating demand has a short

demand period which can be as short as five minutes, but generally demand periods are of 15, 30 or 60 minutes [Buffington and Wolf, 2005; Schedule "K", 2005; Schedule LGS, 2005]. The utility companies use the period with the highest average demand for billing demand charges in any month.

At this point, it may be worth mentioning that not all the utility companies charge their customers based on energy and demand both. Also, there is no specific ratio or number of utility companies that charge based on energy only and do not include demand in their bills. For the present research work, demand period has been assumed to be a 15 minutes interval. The calculation of the demand can be explained with a simple example. Assume that the demand pattern for any particular process is as given in Table 1.1. 
The average demand charged to the facility for this 15 -minute interval can be calculated as,

$$
\begin{aligned}
\text { Demand charged }(\mathrm{kW}) \quad & =\{10 * 2+12 * 4+2 * 7+10 * 2\} / 15 \\
& =6.8 \mathrm{~kW}
\end{aligned}
$$

Table 1.1: Example demand for a 15-minute interval

\begin{tabular}{|c|c|}
\hline Demand (kW) & Time units for this demand \\
\hline 10 & 2 \\
\hline 12 & 4 \\
\hline 2 & 7 \\
\hline 10 & 2 \\
\hline Total & $\mathbf{1 5}$ \\
\hline
\end{tabular}

The demand will be calculated the same way for each of the 15-minutes intervals. Finally, the facility will be charged for the maximum of all these calculated values for each 15-minutes interval during the billing month. It may be noted that in some cases, the demand rate is also a variable charge either based on the time of the day or the year [Industrial Rates, 2005; Schedule 20, 2005; Schedule "B", 2005; Schedule "C", 2005; Schedule "K”, 2005].

The main component or the machine that is responsible for the energy consumption in the turning process is the motor associated with the lathe, $\mathrm{CNC}$ or any other machine used in the process. The following section explains the main concepts related to the motors, their usage, and the consumption of energy by the motors.

\subsection{Motors}

Almost every commercial or industrial facility is a user of motor systems. Motors represent the largest single use of electricity in most plants. A representative figure of 
percentage of overall electricity used by motor-driven equipment in each sector is given as follows [Nadel et al., 2002]:

Utilities: $\quad 89 \%$

Residential: $\quad 38 \%$

Commercial: $37 \%$

Industrial: $\quad 70 \%$

Motor driven equipment account for almost $70 \%$ of all electricity consumed in industrial facilities. In some energy intensive industries such as chemical industries, it may be as high as $90 \%$. Motors are so important in the manufacturing industries because they convert electrical energy into mechanical energy. Motors are designed to perform this function efficiently, but in practice they may not be operated at their highest efficiency level. The factors responsible for inefficient use will be discussed in the following section. The opportunity for savings with motors rests primarily in their selection and use. The selection means by choosing the high-efficiency motors available in the market and correct size required for the application.

According to the National Electrical Manufacturers' Association [EC\&M, 2001], more than 1.2 million integral electric motors are sold every year for different applications. As per the Department of Energy data, it is estimated that the NEMA Premium efficiency motor program could save more than 5,800 gigawatts of electricity, and prevent the release of nearly 80 million metric tons of carbon into the atmosphere over the next 10 years. Therefore it is very important to know the needs before we select the type and size of the motor(s) for any application.

Since motors consume so much energy, efficient operation of the motors can lead to significant savings. One of the savings that is often quoted is the demand savings. One of the case studies states [EC\&M, 2001]: "By reducing demand during times of shortage, we can lower the cost of energy for all power customers in California.... A 10\% reduction in peak demand could lead to a $50 \%$ reduction in the wholesale price of electricity. Load 
management is the only near-term solution that can help us weather the perfect storm that struck California's electricity industry."

It is clear that consideration to the change out to more efficient motors can save lot of money for the manufacturing industries. The Energy Policy Act of 1992 (EPACT) now outlaws the manufacture of most standard efficiency motors, so only premium-efficiency motors can be made. The term "premium-efficiency" appears to be replacing the commonly used terms "energy-efficient" and "high-efficiency" when referring to motors with higher efficiency than standard-efficiency motors.

The other factor to be considered for the efficient operation of the motors is the power factor on the motor. It may be noted that if the power factor of a motor is raised from 0.85 to 0.95 at the motor, the current flow to it will be reduced by $11 \%$ and the demand reduced by almost $21 \%$ [EC\&M, 1998]. For efficient operation of the motors, it is very important to maintain a good power factor value at the motor. Some of the reasons that may lead to inefficient usage of the motors are described in the following sections.

\subsubsection{Idle Running}

Motors with idle running have no-load losses. The direct power savings can be obtained by shutting off idling motors which requires constant supervision or automatic control. Generally, no-load power consumption is considered unimportant but the idle no-load current is frequently 25 to 40 percent of the nameplate full load current, while the power draw or no load loss is only 4 to $8 \%$ of the name plate horsepower [Mate, 2002].

\subsubsection{Efficiency at Low Load}

The motors run at different loads based on the unit it is driving. In some cases the load factor may be as low as $25 \%$ or even lesser. In case of partial loads, the efficiency of the motor may be reduced significantly based on the motor capacity and the design. 
The use of oversized motors is fairly common in most of the facilities because of the following conditions:

- Plant personnel may not know the actual load and to be conservative, select a motor with larger capacity than necessary.

- To ensure that the unit will have ample power, the designer or supplier may suggest a motor driver that is substantially larger than the actual requirements. Rarely, the maximum load is developed on the motor that is driving the equipment and most integral horsepower motors can be safely operated above the full-load rating for short periods without hurting the performance of the motor.

- When a motor fails and a replacement is needed, the personnel install the next larger motor if the correct motor size is not available. The oversized unit continues in use until the plant personnel realize the loss of energy.

- A larger capacity motor is installed for an expected increase in the driven equipment load which never happens.

- The process requirements may have reduced over time and the original motor is still in use.

- For some loads the starting torque requirement is substantially greater than the running torque, and oversized motors are a frequent choice.

The facilities should make sure that none of the discussed procedures are contributing to the inefficient operation. Replacement of underloaded motors with smaller motors will allow a nearly fully loaded smaller motor to operate at a higher efficiency. The identification of oversized motors requires analysis of the load over a representative period of time. Other motors at the plant can often be used as replacement, reducing or eliminating the investment required for new motors. Scheduling the changes to coincide with maintenance of the motors minimizes the installation costs. Figure 1.3 presents the effect of load on efficiency of motors ranging from 1-HP to 10-HP (data from MotorMaster+4.0) [Best Practices, 2005]. It is evident that motors with a load factor less than $50 \%$ will have very low efficiency since the efficiency drops drastically below the load values of $50 \%$. Therefore the facilities should make sure that all the motors are 
running close to the rated load factor or in a range of $75 \%-95 \%$ load factor to have the highest efficiency.

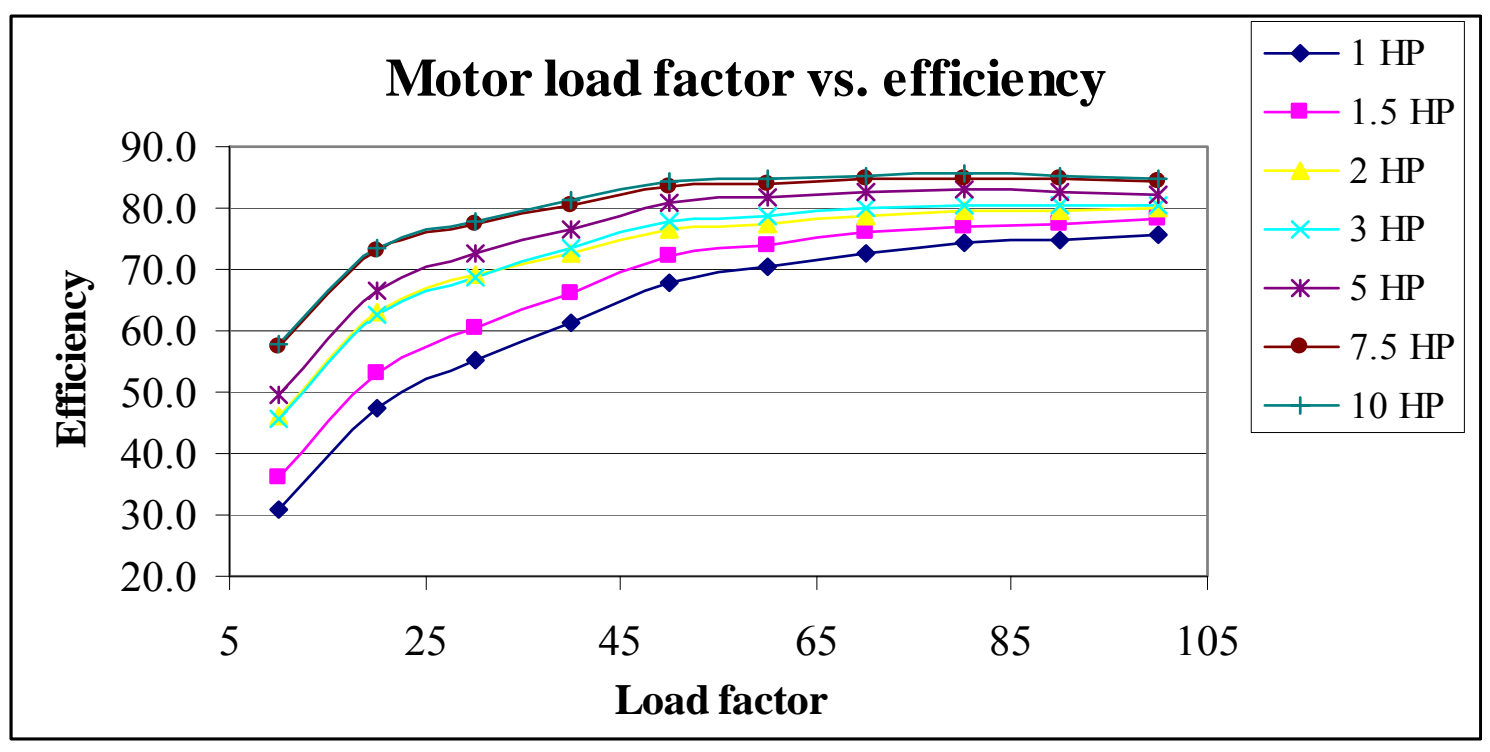

Figure 1.3: Effect of load factor on efficiency

\subsubsection{High-Efficiency Motors}

Use of high-efficiency motors should be promoted to minimize the energy required to operate the motors. In general, premium paid for high-efficiency motors has a payback of less than two years. Manufacturers normally supply motors of standard design since they have lower cost. Because of competitive pressure, these standard motors are likely to be less efficient, have a lower power factor, and are more difficult to rewind.

\subsection{Impact of Energy Cost on Profitability}

Some people may think that the cost of energy is not important, since the total contribution of energy cost to the final cost of the product is $5 \%$ or lesser in a machining company. It may be noted that many of the machining or other industries have their net profit margins in the range of $2 \%-5 \%$, with only a few of them over $5 \%$. In fact, in some cases the net profit margin for many of the industries is below $2 \%$. Some of the companies and their net profit margins along with their total sales for last 12 months [MSN Money, Oct. 5, 2005] are presented in Table 1.2. 
Table 1.2: Example companies and their net profit margin

\begin{tabular}{|c|c|c|}
\hline \multirow{2}{*}{ Company Name } & Sales & Net Profit Margin \\
\hline & \multicolumn{2}{|c|}{ Last 12 months as on Oct 5, 2005} \\
\hline Commercial Metals Company & 6.3 Billion & $4.00 \%$ \\
\hline Kennametal Inc. & 2.3 Billion & $5.20 \%$ \\
\hline Metals USA, Inc. & 1.7 Billion & $5.00 \%$ \\
\hline RTI International Metals & 273.4 Million & $4.70 \%$ \\
\hline Titanium Metals Corporation & 596.2 Million & $19.80 \%$ \\
\hline American Axle \& Manufact. Holdings, Inc. & 3.4 Billion & $2.90 \%$ \\
\hline Arts-Way Manufacturing Co. Inc. & 14.4 Million & $11.1 \%$ \\
\hline Knape \& Vogt Manufacturing & 157.4 Million & $2.00 \%$ \\
\hline Modine Manufacturing Co. & 1.6 Billion & $4.20 \%$ \\
\hline Barnes Group Inc. & 1.0 Billion & $4.20 \%$ \\
\hline LMI Aerospace, Inc. & 93.5 Million & $4.00 \%$ \\
\hline WSI Industries, Inc. & 14.7 Million & $0.70 \%$ \\
\hline SIFCO Industries, Inc. & 80.5 Million & $-5.20 \%$ \\
\hline
\end{tabular}

It is now clear that even a small improvement in the productivity or reduction in the input cost can be of a competitive advantage strategy for a company. With so many companies having a net profit margin less than $5 \%$, any cost savings or productivity improvement definitely will help the company fight the competition in the market. With this idea in mind, the present research focuses on the machining processes with integrated energy cost component. Even though the cost of energy is not significant in many of the machining industries, the analysis on the behavior of different parameters when optimized along with the cost of energy will be interesting to explore the new aspects of machining economics.

Based on the models developed in the literature, it is noted that the cost components and the constraints can be organized to formulate the problem of minimizing the cost as a geometric programming problem. Also, one advantage with the geometric programming formulation is that, even though the formulation is non-linear and is hard to solve, the 
properties of the geometric programming problem can be used to develop the corresponding dual problem which has linear constraints. Finally, the linear constraints can be solved together to get the global optimum solution, as compared to using some other method with which the optimal solution is not guaranteed. Some of the basic concepts about the geometric programming modeling are explained in the following section.

\subsection{Geometric Programming}

The primal problem in geometric programming [Duffin et al., 1967] is formulated to find the minimum value of a function $\mathrm{g}_{0}(\mathrm{t})$ subject to the following constraints,

$$
t_{1}>0, t_{2}>0, \ldots \ldots t_{m}>0
$$

And,

$$
\mathrm{g}_{1}(\mathrm{t}) \leq 1, \mathrm{~g}_{2}(\mathrm{t}) \leq 1, \ldots \ldots, \mathrm{g}_{\mathrm{p}}(\mathrm{t}) \leq 1
$$

Where,

$$
\begin{array}{ll}
g_{k}(t)=\sum_{i \in J[k]} c_{i} t_{1}^{a_{i 1}} t_{2}^{a_{i 2}} \ldots t_{r}^{a_{i r}} & k=0,1, \ldots, p \\
J[k]=\left\{m_{k}, m_{k}+1, m_{k}+2, \ldots \ldots, n_{k}\right\}, & k=0,1, \ldots ., p
\end{array}
$$

And,

$$
m_{0}=1, m_{1}=n_{0}+1, m_{2}=n_{1}+1, \ldots \ldots \ldots, m_{p}=n_{p-1}+1, n_{p}=n
$$

The exponents $a_{i j}$ are arbitrary real numbers. The variables $t_{1}, t_{2}, \ldots t_{r}$ are called primal variables and the constraints are called primal constraints. It may be noted that the geometric programming formulation has a total of $r$ variables, $n$ terms and $p$ constraints. The objective function has a total of $n_{0}$ terms, the first constraint has a total of $\left(n_{1}-n_{0}\right)$ terms, the second constraint has $\left(n_{2}-n_{1}\right)$ terms, and so on. It is apparent that finding the solution for this problem may be difficult because of the non-linearity involved in the formulation. One of the methods that is frequently used in practice is to formulate the dual problem which has linear constrains and can be solved rather easily. 
The dual problem corresponding to this primal problem is formulated to maximize the following:

$$
v(\delta)=\left[\prod_{i=1}^{n_{0}}\left(\frac{c_{i}}{\delta_{i}}\right)^{\delta_{i}}\right] \prod_{k=1}^{p} \lambda_{k}(\delta)^{\lambda_{k}(\delta)}
$$

Where,

$$
\begin{array}{ll}
\lambda_{k}(\delta)=\sum_{i \in J[k]} \delta_{i} & k=1,2 \ldots, p \\
J[k]=\left\{m_{k}, m_{k}+1, m_{k}+2, \ldots \ldots, n_{k}\right) & k=0,1,2 \ldots, p
\end{array}
$$

And,

$$
m_{0}=1, m_{1}=n_{0}+1, m_{2}=n_{1}+1, \ldots \ldots \ldots, m_{p}=n_{p-1}+1, n_{p}=n
$$

The factors $c_{i}$ are assumed to be positive and the vector variable $\delta=\left(\delta_{1}, \ldots \ldots, \delta_{n}\right)$ is subject to the following linear constraints:

$$
\begin{aligned}
& \delta_{1} \geq 0, \ldots \ldots, \delta_{n} \geq 0 \\
& \sum_{i \in J[0]} \delta_{i}=1
\end{aligned}
$$

And,

$$
\sum_{i=1}^{n} a_{i j} \delta_{i}=0 \quad j=1,2 \ldots, m
$$

The coefficients $a_{i j}$ are real numbers.

\subsection{Need for Research}

Many researchers [Taylor, 1907; Gilbert, 1950; Hitomi, 1991; Agapiou 1992; etc.] have worked on the problem of machining parameter optimization that minimizes the cost of machining. On the other hand, the other researchers [Boston and Kraus 1932; Merchant 1944; Shaw et al. 1952; Cook 1966; etc.] have worked on developing the energy consumption models for machining operations. But the cost of energy was not considered 
as an integral part of the optimization process. Due to increasing cost of energy and the pressure to reduce the energy consumption, the models developed to optimize the machining processes may not prove to be optimal on the level of overall organization.

The current machining economics models optimize the machining cost that includes the cost of machine tool, labor, etc. Since these models do not have any components to address the use of energy, the energy usage and cost are derived based on the results from the process parameter optimization models. At this point, it is interesting that even though the energy cost for the process is an outcome based on these parameters, the models do not address this cost while developing the solution for the process parameters. Once the cost of energy is included, the total cost may go beyond the expected limits. In many energy intensive processes e.g. in chemical industries, the cost of energy may be as high as $10 \%-20 \%$ of the processing cost. This is the driving force that makes everyone think of ways to reduce the energy consumption to minimize the overall cost of machining. In fact, some companies, e.g. General Motors and General Electric, have started many energy conservation projects and the results are considered during the performance review of the managers.

\subsection{Research Objectives}

A mathematical model based on single pass turning operation is used to determine the optimum cutting condition. The model includes the surface finish constraints as well as maximum horsepower (HP) constraint of the motor that is used to run the machine. The main objectives of the present work are as follows.

1. Include the concept of energy as an integral part of optimization in the present mathematical model for single pass turning operation.

2. Develop solution technique for the modified model.

3. Develop user-friendly computer based system to find the solution for given machining parameters. 
4. Perform a sensitivity analysis for different parameters in the model. The parameters include the following:
a. Labor rate
b. Tool cost
c. Unit cost of energy usage $(\$ / \mathrm{kWh})$
d. Unit cost of energy demand $(\$ / \mathrm{kW})$

5. Perform an extensive parameter behavioral analysis and evaluate the results from the proposed model with respect to energy and non-energy oriented criteria.

Based on these research objectives, a high level system diagram is developed and is given in Figure 1.4.

\subsection{Conclusion}

Machining economics is an important element for economic growth of companies. In recent years, reducing supply of energy and increasing energy demand have attracted the attention of manufacturers towards energy usage and conservation considerations. Many researchers have worked on machining economics problems, but the cost of energy has never been considered as an integral part of the optimization problem. This research work is focused on developing the mathematical model for a single pass turning process with energy cost considerations. 


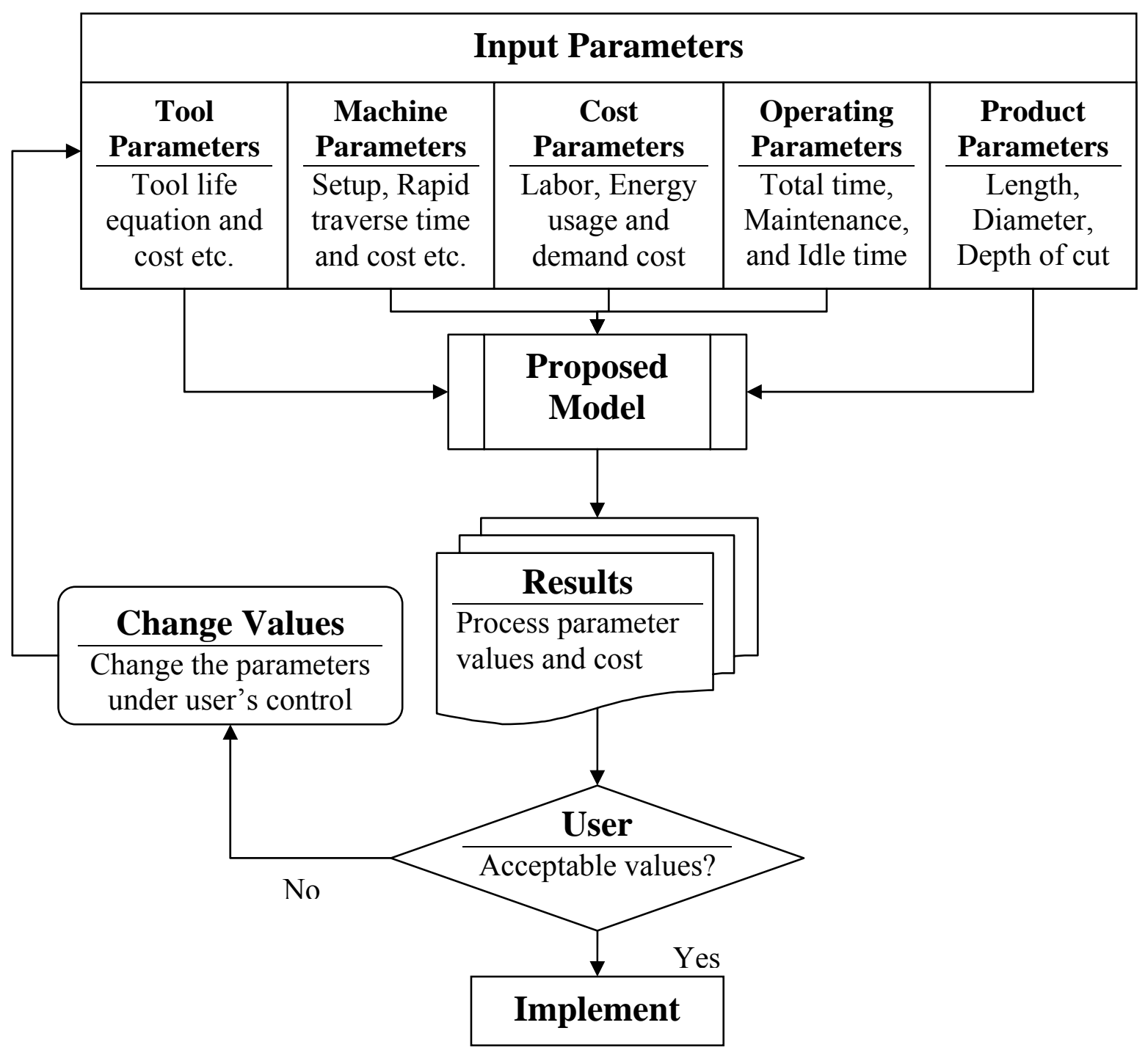

Figure 1.4: System diagram 


\section{Chapter 2}

\section{Literature Review}

\subsection{Machining Cost and/or Time Models}

As early as in 1907, Taylor discovered the need for a model to develop the optimum cutting speed for a single pass turning operation. Since then, many researchers developed different models for turning and other machining processes. Some of different objective functions [Hitomi, 1996] used for the development of optimization models include:

$>$ Minimum production time,

$>$ Minimum production cost,

$>$ A weighted combination of the time and cost,

$>$ Maximum metal removal rate and

$>$ Maximum profit rate

Many solution techniques have been used to find the optimum cutting condition for different processes. But in all the cases, only the cost components related to the labor cost and tool cost were considered which in turn proves to be a mere local optimization of the parameter optimization process. Some of the models developed for machining optimization have been outlined in the following paragraphs.

Selection of machining parameters has been foremost concern in optimizing the machining efficiency. Early work in this area was focused on determining the range of suitable machining parameter through experimental work. Taylor conducted a series of experiments over a period of 26 years and published the work on achieving metal cutting efficiency in "On the art of cutting metals" [Taylor, 1907]. Similar work resulted in the development of machining data handbook [Machining Data Handbook, 1980] that has different process parameter ranges for optimizing the machining cost and time. 
In 1950, Gilbert presented the concept of maximum production rate and minimum cost criteria in "Economics of Machining" [Gilbert, 1950]. Recently, different researchers have developed mathematical models for the selection of optimal machining parameters to meet different objectives such as minimizing the machining time and labor cost or the machining time itself depending on the need for the research. Some of the models are discussed below.

Hitomi [1991] developed the model to determine the optimal machining speed to be utilized on the multiple stages of a flow type automated manufacturing system. Separate models were developed to determine the bottleneck stage, optimal cycle time and optimal cutting speed. The models were developed for different objectives to maximize the production rate, minimize total cost and maximize profit rate.

Agapiou [1992] developed a mathematical model to minimize the cost associated with idle time at different stations. Physical constraints such as surface finish, cutting force and cutting power were considered in the model. It was shown that tool cost per unit piece could be reduced significantly by utilizing the idle time and adjusting the machining parameters accordingly.

Some of the researchers worked on single pass turning operation as opposed to the others who worked on multi-pass operations. Tsai [1986] presented the concept of a breakeven point for multi-pass tuning operation. In some cases when depth of cut drops below a certain point, single pass operation is more economical than the multi-pass turning operation and vice-versa.

Gopalakrishnan and Al-Khayyal [1991] presented an analytical tool for the selection of machining parameters in single pass turning operation. The problem had been formulated to minimize the turning cost (machining time and tool wear cost) and to determine the optimal feed and speed for the operation. Geometric programming had been used to find the optimal solution. 
Ahmad and Haque [2001] developed a Genetic Algorithm Optimization Toolbox to optimize the process parameters for machining rotational components in multiple pass turning operation. They developed the model with minimizing machining time as objective function subject to different constraints for machine capacity, limits on feed rate, depth of cut and cutting speed etc.

Tan and Creese [1995] developed a generalized machining parameter selection model with an approximation optimization solution approach for multi-pass turning operation. The model is formulated to minimize the machining cost with parameters as number of passes, cutting speed, feed rate and depth of cut. The model is formulated with cost minimization as the objective function.

Lee and Tarng [2000] reported an investigation of optimal cutting parameters for maximizing production rate or minimizing production cost in multistage turning operation. The machining model is constructed based on a polynomial network since they can learn the relationships between cutting parameters (cutting speed, feed rate, and depth of cut) and cutting performance (surface roughness, cutting force, and tool life) through a self-organizing adaptive modeling techniques. The optimal cutting parameters are determined by an optimization algorithm using a sequential quadratic programming method. The objective function of cost minimization or production rate maximization is subjected to the constraints of permissible surface roughness and cutting force and a feasible range of cutting parameters.

Shin and Joo [1992] incorporated the preventive tool replacement strategy in the model for optimization of machining conditions in a multi-pass turning operation. Machine idle time is also considered as a variable in the model. The model is solved using dynamic programming technique.

Al-Ahmari et al. [2001] presented a mathematical model for multi-pass turning operation with constraints. They modified the model presented by Shin and Joo [1992] and presented a non-linear model for the machining optimization problem. In the paper, they 
reported that the solutions obtained by the methods discussed by Shin and Joo [1992] did not yield the optimal solution. The same model was used by Gupta et al. [1995] wherein they attempted to solve the model using two phase method. They also reported that the method suggested by Gupta et al. was very time consuming in many cases. They also gave the code in LINGO, a non-linear programming solver. Finally, they compared the results from their model to that from the models proposed by Shin and Joo and Gupta et al. It was shown that in most of the cases they got the better solutions.

Wang et al. [2002] proposed a deterministic model for optimization of cutting conditions for single pass turning operations. They analyzed the equation for minimum time per tool as opposed to minimum cost per piece and said that the characteristics to minimize time and cost are similar. They used the extended Taylor's tool life equation in the formulation. Also, the formulation proposed by them considered only the feed and speed as variables. They considered the following constraints in their model:

1. Machine tool speed and feed boundary constraints,

2. Machine tool force constraints,

3. Machine tool maximum power and torque constraints,

4. Components surface roughness constraints, and

5. Minimum and maximum tool life limits

Finally they compared the results from their model to the ones given in different handbooks. The results revealed that solutions from the proposed model were better than the ones given in the handbooks.

Saravanan et al. [2003] proposed solution techniques using Genetic Algorithm (GA) and Simulated Annealing (SA). They considered the optimization model to minimize the production cost with the following constraints:

1. Cutting force constraint

2. Power constraint

3. Chip-tool interface temperature constraint

4. Cutting speed constraint 
5. Regression based dimensional accuracy constraint

6. Surface finish constraint

Apart from the machining cost, tool cost and tool replacement cost, they also considered the idle time cost for the machine. It may be noted that the example problem discussed in the paper had varying diameter as opposed to the traditional constant diameter problems. Finally they compared the results from Genetic Algorithm and Simulated Annealing. It was shown that the SA algorithm resulted into a better solution than the GA algorithm.

Liang et al. [2001] presented the multipass machining model to optimize not only the machining speed, depth of cut and the feed rate but also the tool adjustment interval and the amount of the adjustment. The extended Taylor's tool life equation was used to define the life of the tool in the model. The quality loss was defined to be a function based on some quality characteristic deviation from a predefined target value, a scrap cost and the tolerance limit for the characteristic. They assumed that the tool would be replaced before a new pass, even if the remaining life of the tool was a significant portion of the total tool life. The model was developed for both the small parts, where one tool may be used for more than one part, and the large parts where several tools may be needed for one part. Finally the model was proposed to minimize the cost of machining.

Prasad et al. [1997] developed a PC-based generative CAPP system for process parameter optimization. The objective function is based on minimizing the production time subject to the constraints for parameter bounds, surface roughness, maximum available power etc. A combination of geometric programming and linear programming was used to find the solution for the problem. Finally they reported savings of $11.4 \%$ to $21 \%$ in terms of computational time to find the solution. However, the solutions obtained were same as the ones already in the literature.

Koulamas [1991] presented an analytical model to determine the optimal machining condition parameter (cutting speed and feed) along with the optimal tool replacement policy. Apart from considering the cost of labor and tool in the cost minimizing objective 
function, he introduced a penalty cost for the unforeseen tool failures during the production. Finally, the objective function was constrained with surface finish, maximum allowable feed or maximum available horsepower requirements.

Chen and Tsai [1996] developed a simulated annealing and Hook-Jeeves pattern search based algorithm for optimization of multi-pass turning operations. Minimization of machining cost was considered as the objective function subject to the set of constraints related to parameter bounds, surface finish constraints, chip-tool interface temperature constraints, tool life constraint etc. The cutting process was a combination of multi-pass rough machining and finishing operation.

It is clear now that the problem of machining parameter optimization has been of great interest to the operation research group. Starting from simple experiments based results, the problem has been considered with respect to different aspects of the parameter optimization dealing with the cost components, tool replacement decisions, single and multipass operations etc. Apart from this research group who concentrated on the economics of machining, the other group of researchers looked at this interesting problem with different eyes and developed the model to address the issues in terms of energy consumption and/or energy requirement for the machining operations. Some of the work in this area has been discussed in the following section.

\subsection{Energy Consumption Models}

Many researchers have worked in the area of power or energy consumption models for different manufacturing processes. Merchant [1944] formulated the equations for the total work done in cutting which was represented as sum of work done with respect to friction and shearing. Shaw et al. [1952] derived equations for energy consumption per unit volume with its components as friction, shear, surface, and momentum energy. But the surface and the momentum energy components were negligible with respect to the other two components. The theory proposed by him was validated by the experiments 
conducted by Cook [1966]. Cook discovered one more component as chip curl energy which was approximately $5 \%$ of the total energy required.

Dautzenberg et al. [1981] presented equations for deformation in orthogonal cutting. They combined the power from the force in shear plane and friction force in tool and chip contact zone. The methods developed by them required the knowledge of the shear angle which is very difficult to obtain.

Boston and Kraus [1932] performed experiments and came up with an empirical equation for energy consumed per chip that used feed rate, width and depth of cut and some material specific constants. They used the results from this equation to find the specific cutting energy. Since this equation used material specific constants and was based on empirical results, it requires performing experiments for almost every combination of material which limits the application for economic reasons.

Kronenberg [1940] performed number of experiments and develop an empirical equation to determine the power requirement. He used the unit power, the area of the cut and some material constants as components in the equation. Again in this case, the economic viability of the application is questionable because of the empirical results.

One of the methods presented by Boston [1951] for determining the power requirements in turning process uses the force and the cutting velocity. He used the products of the two values and scaled it with a constant number to get the horsepower (HP) requirements. The other method suggested by Boston was to take the products of the unit horsepower and material removal rate. Unit horsepower is known as the specific energy and is defined in terms of the total cutting force, width and depth of cut. Also, this value depends on the type of cutting and the workpiece material.

With respect to the turning process, Brierley and Siekmann [1964] derived equation for the power requirement per revolution with respect to the tangential and longitudinal forces and velocities. They showed that the tangential power component was more than 
the longitudinal power component since the velocity in the longitudinal directions was very small. The determination of power requirement for a cut using this equation requires the user to know all the forces in advance which is very difficult. One major difference in the approaches by Boston and Brierley was that Brierley used the force components rather than using the overall force.

\subsection{Conclusion}

It is now evident that we have had two different streams of researchers, one dealing with the cost and/or time optimization and the other deriving the power requirements. Even though the cost of energy was not directly considered in any of the research done so far, the power requirements may be presented in terms of the energy costs. Therefore it is worth researching the impact of energy cost on the machining parameters. Chapter 3 deals with developing the mathematical model for the machining parameter optimization which considers not only the cost of tool and labor but also the cost of energy as an integral part of the optimization process. At this point, it may be noted that the cost of energy is not very significant but the scarcity of the energy and increasing energy costs cannot be ignored in machining parameter optimization process. 


\section{Chapter 3}

\section{The Model}

The main purpose of this research is to include the concept of energy economics in the present machining economics models to find the optimal machining parameters. Thus the model developed in this research is intended to minimize not only the labor cost and the tool cost but also the costs associated with energy usage. The energy cost includes the electricity usage cost and the demand cost. This work focuses on incorporating only the direct energy used by the motor for the turning process. The other part of the energy usage or the indirect energy usage e.g. lighting, heating, air conditioning etc. have not been included in this model. As shown in the literature, cutting speed, feed and depth of cut are the main parameters to be considered for the parameter optimization process. Many a times, the depth of cut is decided in advance [Gopalakrishnan and Al-Khayyal, 1991; Hitomi, 1996]. Therefore, depth of cut is assumed to be constant in the model. Since the present model is an attempt to bolster the energy conservation concept in the process models, a single pass turning operation is considered to simplify the solution approach.

To minimize the cost of energy along with the cost of labor and cost of tool, there is a need to develop an appropriate mathematical model that will find the optimal process parameters for a single pass turning operation. Once this model is validated, it can easily be extended to any number of passes, or other machining operations. Even the depth of cut can be included in the model but this concept is out of the scope of this research and will not be discussed in this thesis.

In the present research, a constrained mathematical model has been developed to derive the optimal cutting speed and feed. The basic criterion is to minimize the total cost of the operation. The constraints used are for the maximum horsepower (HP) available from the motor and the surface roughness requirement. A general outline of the model will be illustrated in a later section. 


\subsection{Assumptions}

1. All the constants in the extended Taylor's tool life equation are known.

2. The electricity rate (per unit usage and demand cost) is known and is constant.

3. Demand cost is based on the average demand level created by the product under consideration.

4. Unit labor and tool cost is available.

5. A single pass turning process is considered.

6. Depth of cut is constant for the pass under consideration.

7. There is no limit on the cutting speed and feed values.

8. Machining cost is considered only for the time when actual cutting is done which excludes pre-travel and post-travel distances.

9. The efficiencies of the motor at different load ranges are known.

10. There is no limit on the product demand.

\subsection{Objective Function}

The objective function consists of the following terms.

1. Labor cost,

2. Tool cost,

3. Electricity cost, and

4. Demand cost

All these costs are dependent on the time of machining which is defined as $T_{m}$ and is given as,

$$
\begin{aligned}
& T_{m}=\frac{\text { length of the workpiece }}{\text { feed rate } * \text { rotational speed }} \\
& T_{m}=\frac{l}{f * N}
\end{aligned}
$$


The value of rotational speed in terms of speed and workpiece diameter is expressed as,

$$
N=\frac{12 * V}{\pi * D}
$$

Where $\mathrm{V}$ is in feet/minute and $\mathrm{D}$ is given in inches. Substituting this value in the equation (1) for time of machining,

$$
T_{m}=\frac{\pi^{*} D^{*} l}{12 * f * V}
$$

Equation (3-3) for the cutting time is used to derive different costs associated with the machining.

\subsubsection{Labor Cost}

Labor cost is the cost related to the labor time spent for the time of machining. Since the time of machining is defined as $T_{m}$, labor cost is simply the labor time multiplied by the labor cost per unit time $\left(L_{r}, \$ /\right.$ minute $)$ and is mathematically expressed as,

$$
L C \quad=\left(\frac{\pi * D^{*} l}{12 * f * V}\right) * L_{r}
$$

Or,

$$
L C \quad=C_{1} f^{-1} V^{-1}
$$

Where $\mathrm{C}_{1}$ is a constant and can be expressed as,

$$
C_{1}=\left(\frac{\pi^{*} D^{*} l^{*} L_{r}}{12}\right)
$$

\subsubsection{Tool Cost}

Tool cost is the cost related to the labor cost for changing the tool and the actual cost of the tool being used. Both these costs are related to the number of times the tools fails during the machining operation. 
To derive the number of times the tool fails, the extended Taylor's tool life equation (Ermer and Kromordihardjo 1981, Bhattacharya et al. 1970) is used which is given as,

$$
V * T^{n *} f^{m *} d^{p}=C
$$

Where $T$ is the tool life (minutes), $d$ is the depth of cut (inch), $n, m, p$ and $C$ are constants. Equation (3-7) can be represented as follows,

$$
T=\frac{C^{1 / n}}{V^{1 / n} * f^{m / n} * d^{p / n}}
$$

Therefore the average number of times a tool fails, during the machining time, can be given as the ratio of machining time and the tool life and is expressed as,

$$
\frac{T_{m}}{T}=\left(\frac{\pi * D^{*} L^{*} C^{-1 / n} * d^{p / n}}{12}\right) * V^{\frac{1}{n}-1} * f^{\frac{m}{n}-1}
$$

Therefore the cost associated with the tool (TC) will be expressed as,

$$
\begin{aligned}
T C= & \text { tool change time cost }+ \text { actual tool cost } \\
= & \text { number of times tool fails*labor rate*tool change time }+ \text { number of } \\
& \text { times tool fails*average tool cost for sharpening or replacing the tool } \\
= & \frac{T_{m}}{T} * L_{r} * T_{C}+\frac{T_{m}}{T} * T_{\text {cost }}
\end{aligned}
$$

Where, $T_{c}$ is the time (minutes) to change a tool and $T_{\text {cost }}(\$)$ is the cost of tool/edge. Finally, the cost associated with the tool can be expressed as,

$$
\text { TC }=C_{2} * V^{\frac{1}{n}-1} * f^{\frac{m}{n}-1}
$$

Where $C_{2}$ is a constant and can be expressed as,

$$
C_{2} \quad=\left(\frac{\pi * D^{*} L^{*} C^{-1 / n} * d^{p / n}}{12}\right) *\left(L_{r} * T_{c}+T_{\text {cost }}\right)
$$




\subsubsection{Electricity Cost}

Electricity cost can be expressed as the amount of electricity used multiplied by the cost per unit of electricity. The amount of electricity used $(E U)$ is the time of machining multiplied by the power $(\mathrm{kW})$ requirements for the turning operation.

Thus, the equation for the cost of electricity can be given as,

$$
E C \quad=\left(\frac{T_{m}}{60}\right) * D U * E R * \frac{1}{\eta}
$$

Where $D U$ is the power required $(\mathrm{kW})$ for machining and $E R$ is the energy usage rate ( $\$ / \mathrm{kWh}$ ). A factor of 60 has been used in order to convert the value of $T_{m}$ from minutes to hours. The value of $T_{m}$ can be expressed in terms of speed $V$ and feed $f . \eta$ is the efficiency of the motor used for turning process.

Power requirements $(D U)$ can be calculated using the horsepower (HP) constraint [Ermer et al., 1981; Gopalakrishnan and Al-Khayyal, 1991; Tan and Creese, 1995] for the turning operations and can be expressed as,

$$
D U=C_{m} * V^{b} * f^{c} * d^{e} * C_{k W / H P}
$$

Where, $C_{k W / H P}$ is the conversion factor $(0.746 \mathrm{~kW}$ per HP) from HP to $\mathrm{kW}$. Therefore, the final equation for the electricity cost can be expressed as.

$$
\begin{aligned}
& \text { EC } \quad=\left(\frac{1}{60}\right) *\left(\frac{\pi * D^{*} l}{12 * f^{*} V}\right) *\left(C_{m} * V^{b *} f^{\left.c * d^{e} * C_{k W / H P}\right) * E R * \frac{1}{\eta}}\right. \\
& \text { EC } \quad=C_{L} * V^{b-1} * f^{c-1}
\end{aligned}
$$

Where $C_{L}$ can be considered as a constant, assuming that the efficiency of the motor is known and is constant. It may be noted that the efficiency of the drive motor depends on the power requirement, and therefore on the speed and feed for the process. Since there is no mathematical relation between the efficiency and the process parameters, and for 
convenience, the final value of the efficiency will be determined through an iterative process in which the starting value of the efficiency is based on the current literature values for speed and feed and then, in each iteration its value will be based on the speed and feed values obtained in the previous iteration. The constant $C_{L}$ can be expressed as,

$$
C_{L}=\left(\frac{1}{60}\right) *\left(\frac{\pi * D * l}{12}\right) *\left(C_{m} * d^{e} * C_{k W / H P}\right) * E R * \frac{1}{\eta}
$$

\subsubsection{Demand Cost}

Demand cost can be expressed as the power requirements ( $D U$, in $\mathrm{kW})$ multiplied by the cost of unit $\mathrm{kW}$ power. It may be noted that the unit demand cost is given in terms of $\$ / \mathrm{kW}$-month, therefore the cost of demand must be considered with respect to the number of pieces the machine produced per month.

At this point, it is necessary to understand that the products processed on the machine may have different power requirements; therefore the demand cost share should be considered based on the prior knowledge of the schedule on any single machine. It is assumed that the average number of products that will share the demand cost is known in advance and will be used to derive the demand cost for a single pass. Also, as discussed in Section 1.4, the demand cost is calculated based on 15-minutes or similar intervals. A 15-minutes interval approach has been considered for the present model development; but it can be changed in the input sheet developed for the model. A correction factor $(C F)$ is introduced in the model to estimate the average demand peak. Assuming that the company under consideration is charged based on a 15-minutes interval and the power requirement is there only during the actual machining and rapid traverse times, the proposed correction factor can be calculated as given in Table 3.1. The actual value of the demand cost per piece may vary a little from the one calculated using this equation but the effect will be very small. Since the value of machining time $T_{m}$ required to calculate the machining time is not known in advance, the iteration process will be started based on the value calculated with the values of speed and feed from the current literature. 
Table 3.1: Proposed correction factor for demand cost calculations

\begin{tabular}{|c|c|}
\hline Case & Correction factor (CF) \\
\hline Machining time, $T_{m} \geq 15$ minutes & 1 \\
\hline $\begin{array}{c}\text { Machining time, } T_{m}<15 \text { minutes and } \\
T_{m}+T_{r}<15, \text { where } T_{r} \text { is rapid traverse time } \\
\text { and } D T \text { is the demand during rapid traverse }\end{array}$ & $\frac{\left(T_{m} * D U\right)+\left(T_{r} * D T\right)}{\left(T_{m}+T_{r}\right) * D U}$ \\
\hline Machining time, $T_{m}<15$ minutes and \\
$T_{m}+T_{r} \geq 15$, where $T_{r}$ is rapid traverse time \\
and $D T$ is the demand during rapid traverse
\end{tabular}

It may be noted that the demand charge is indirectly related to the demand used during rapid traverse time $(D T)$. Therefore, it has been used to derive the correction factor for the actual demand cost during the single pass operation. On the other hand, the energy used during the rapid traverse time does not affect the energy usage during the actual machining operation. In fact, the energy used during this time is dependent on the rapid traverse time $\left(T_{r}\right)$ and $D T$, which are constant; therefore the corresponding energy charge will be constant and can be ignored for the analysis. Finally, the equation for the demand cost can be given as,

$$
D C=C F *\left(\frac{1}{n_{u}}\right) * D U * D R * \frac{1}{\eta}
$$

Where $n_{u}$ is the representative number of units produced in one month using the same machine and $D R$ is the demand rate $(\$ / \mathrm{kW})$. In other words, $\left(1 / n_{u}\right)$ may be represented as the demand cost share by one unit produced on the same machine. This expression for the demand cost is very similar to the one developed for the energy usage cost in equation (313), except that there is no machining time term in the demand cost. At this point, it is obvious that using this equation will result in an extra dual variable with the same number of constraints, which will increase the difficulty level of the problem. If the machining time term is incorporated into this equation, the demand cost term can be written together with the energy usage cost term, which reduces the degree of difficulty of the geometric programming formulation. To accomplish this, the number of units to be 
produced can be considered based on the total time of machining per unit and the total time for the machine in a given month. The total time for a machine consists of the following components.

1. Machining time

2. Tool change time

3. Rapid traverse time

4. Machine setup time

5. Maintenance time

6. Idle time

It is assumed that there is no limit on the demand. Maintenance time and idle time are usually constant, i.e. they are independent of the machining time or feed and speed values. Also, an approximate value for the number of units can be estimated using the existing models and can be used to calculate the total time for the tool change, rapid traverse and machine setup. Finally, these time values can be subtracted from the total time for the machine, which will then result into the total available machining time on the machine. For example, assume that the machine has a total of 8 hours of available time per day and on the average, 20 minutes are spent for maintenance every 8 hours while the idle time is estimated as 30 minutes which may consist of lunch time etc. Assuming that the current models result into a tool change time of 0.5 minutes per unit, and it takes 2 minutes and 3 minutes for rapid traverse and machine setup per unit respectively; the total time can be expressed as follows,

$$
\begin{aligned}
& 8 \text { hours *60 minutes/hour*30 days/month } \\
& \qquad \begin{aligned}
\text { (430*30) minutes } & \left.=n_{u} *\left(T_{m}+0.5+2+3\right)+(20+30) * 30 \text { days/month }\right\} \\
12,900 \text { minutes } & =n_{u} *\left(T_{m}+5.5\right)
\end{aligned}
\end{aligned}
$$

If the current models result in feed and speed values that lead to a machining time of 14.5 minutes, the approximate number of units can be calculated as,

$$
12,900 \text { minutes } \quad=n_{u} *(14.5+5.5)
$$


or,

$$
n_{u} \quad=\frac{12,900}{14.5+5.5} \text { or } 645 \text { units } / \text { month }
$$

Now, going back to the equation for the total time on the machine and using this approximate number of units per month for everything else except for the machining time, the equation can be rewritten as follows,

$$
\begin{aligned}
12,900 \text { minutes } & =n_{u} * T_{m}+n_{u} * 5.5 \\
& =n_{u} * T_{m}+645 * 5.5 \\
& =(12,900-645 * 5.5) / T_{m} \\
& =9352.5 / T_{m} \\
& =T_{a m} / T_{m}
\end{aligned}
$$

Where, $T_{a m}$ is a temporary constant, which is called here as the available machining time for the machine. This expression for the number of units can be used in the demand cost expression. Since this expression is based on approximations, an iterative process will be used to find the final values for feed and speed.

The algorithm will start with the values from the current literature model and will update the values to the ones calculated in the latest step of the iterative process. Once the calculated values are either exactly the same or significantly close to the ones from the previous iteration, the process will terminate and the current values will be considered as the final solution. Now, the equation for the demand cost can be given as,

$$
D C=C F *\left(\frac{T_{m}}{T_{a m}}\right) * D U * D R * \frac{1}{\eta}
$$

Substituting the values of $T_{m}$ and $D U$ as it was done for the electricity cost, the final equation for the demand cost can be expressed as,

$$
D C=C F * \frac{\left(\frac{\pi * D^{*} l}{12 * f^{*} V}\right)}{T_{a m}} *\left(C_{m} * V^{b} * f^{c} * d^{e} * C_{k W / H P}\right) * D R * \frac{1}{\eta}
$$




$$
D C \quad=C_{M} * V^{b-1} * f^{c-1}
$$

Where $C_{4}$ can be considered as a constant, assuming that the efficiency of the motor is known (as explained in Section 3.2.3), and is expressed as,

$$
C_{M}=C F *\left(\frac{\pi * D * l}{12 * T_{a m}}\right) *\left(C_{m} * d^{e} * C_{k W / H P}\right) * D R * \frac{1}{\eta}
$$

Therefore the total energy cost (TEC) can be obtained using the sum of the electricity cost and the demand cost.

$$
\begin{aligned}
\text { TEC } & =C_{L} * V^{b-1} * f^{c-1}+C_{M} * V^{b-1} * f^{c-1} \\
& =C_{3} * V^{b-1} * f^{c-1}
\end{aligned}
$$

Where,

$$
C_{3} \quad=C_{L}+C_{M}
$$

All the cost components can then be combined to define the total cost for the machining. The proposed model formulation is given in the following section.

\subsection{Primal Problem}

Considering the equations developed by researchers in the past [Ermer et al., 1981; Gopalakrishnan and Al-Khayyal, 1991; Tan and Creese, 1995] and including the cost of energy in the objective function, the primal problem can be expressed as minimizing the sum of all the cost components explained in Section 3.2 and can be given as follows.

$$
\operatorname{Min} C_{u}=C_{1} V^{-1} f^{-1}+C_{2} V^{\frac{1}{n}-1} f^{\frac{m}{n}-1}+C_{3} V^{b-1} f^{c-1}
$$

Subject to,

$$
\begin{array}{ll}
C_{m}^{\prime} V^{b} f^{c} \leq 1 & \text { (Power constraint) } \\
C_{s}^{\prime} V^{g} f^{h} \leq 1 & \text { (Surface finish constraint) } \\
V, f \geq 0 &
\end{array}
$$


Where,

$$
C_{m}^{\prime}=\frac{C_{m} * d^{e}}{H P_{\max }} \quad \text { and } \quad C_{s}^{\prime}=\frac{C_{s} * d^{i}}{S F_{\max }}
$$

The primal problem is the standard form of geometric programming. The dual problem can be developed from this primal problem and is given in the following section.

\subsection{Dual Problem}

$$
\operatorname{Max} Z=\left(\frac{C_{1}}{W_{1}}\right)^{W_{1}}\left(\frac{C_{2}}{W_{2}}\right)^{W_{2}}\left(\frac{C_{3}}{W_{3}}\right)^{W_{3}}\left(C_{m}^{\prime}\right)^{W_{4}}\left(C_{s}^{\prime}\right)^{W_{5}}
$$

Subject to,

Orthogonality conditions:

$$
\begin{aligned}
& -W_{1}+\left(\frac{1}{n}-1\right) W_{2}+(b-1) W_{3}+b W_{4}+g W_{5}=0 \\
& -W_{1}+\left(\frac{m}{n}-1\right) W_{2}+(c-1) W_{3}+c W_{4}+h W_{5}=0
\end{aligned}
$$

\section{Normality condition:}

$$
\begin{aligned}
& W_{1}+W_{2}+W_{3}=1 \\
& W_{1}, W_{2}, . . W_{5} \geq 0
\end{aligned}
$$

Based on the discussion presented in Section 1.5.2, it may be noted that the motors run at the highest efficiency in the range of $75 \%$ to $95 \%$ or so. Therefore it is logical to conclude that the corresponding horsepower constraint should be loose to force the maximum value of load factor to be less than 1.0. Once the horsepower constraint is set to be loose, it is apparent that the corresponding dual variable should be set to zero. Also, as discussed by Gopalakrishnan and Al-Khayyal (1991), the optimum values are obtained when this dual variable is set to be zero. Therefore, forcing $\mathrm{W}_{4}$ to be zero, leads to the following set of equations.

$$
\operatorname{Max} Z=\left(\frac{C_{1}}{W_{1}}\right)^{W_{1}}\left(\frac{C_{2}}{W_{2}}\right)^{W_{2}}\left(\frac{C_{3}}{W_{3}}\right)^{W_{3}}\left(C_{s}^{\prime}\right)^{W_{s}}
$$


Subject to,

$$
\begin{aligned}
& -W_{1}+\left(\frac{1}{n}-1\right) W_{2}+(b-1) W_{3}+g W_{5}=0 \\
& -W_{1}+\left(\frac{m}{n}-1\right) W_{2}+(c-1) W_{3}+h W_{5}=0 \\
& W_{1}+W_{2}+W_{3}=1 \\
& W_{1}, W_{2}, W_{3} \text { and } W_{5} \geq 0
\end{aligned}
$$

Degree of difficulty $(D)$ for a geometric programming is defined as follows.

$$
D \quad=T-(N+1)
$$

Where $T$ is the number of dual variables and $N$ is the number of orthogonality constraints in the dual problem. For the proposed model, the number of dual variables is 4 and the number of orthogonality constraints is 2 . Therefore, the degree of difficulty for the proposed model is,

$$
\begin{aligned}
D & =4-(2+1) \\
& =1
\end{aligned}
$$

Since the degree of difficulty is one, the dual variables can be expressed in terms of a single variable and finally, the values of all the variables in the dual objective function can be substituted with the new values which then can be solved using derivatives techniques. Creese [1979] proposed a model to develop new independent relationships based on the primal and dual relations. This technique is used to develop additional equation(s) for the model which then can reduce the degree of difficulty. The relationship between the dual and primal variables can be expressed in terms of the following equations,

$$
\begin{array}{lllll}
C_{1} V^{-1} f^{-1} & =W_{1} C_{u} & \text { or } & V^{-1} f^{-1} & =\frac{W_{1} C_{u}}{C_{1}} \\
C_{2} V^{\frac{1}{n}-1} f^{\frac{m}{n}-1} & =W_{2} C_{u} & \text { or } & V^{\frac{1}{n}-1} f^{\frac{m}{n}-1} & =\frac{W_{2} C_{u}}{C_{2}}
\end{array}
$$




$$
\begin{array}{llll}
C_{3} V^{b-1} f^{c-1} & =W_{3} C_{u} & \text { or } & V^{b-1} f^{c-1}=\frac{W_{3} C_{u}}{C_{3}} \\
C_{s}^{\prime} V^{g} f^{h} & =1 & \text { or } & V^{g} f^{h}=\frac{1}{C_{s}^{\prime}}
\end{array}
$$

It is assumed that the dual variable corresponding to the surface finish constraint has a positive value in the final solution. It can be shown that different additional equations can be developed using equations (3-37) through (3-40), but they will be non-linear and cannot be used to solve the proposed model unless some heuristic method is used. Therefore, it is suggested to use the derivative techniques i.e. defining all the variables in terms of a single variable, and finally taking the derivative of the objective function. Now, equations (3-33), (3-34) and (3-35) can be simplified to the following equations.

$$
\begin{aligned}
& \left(\frac{1}{n}\right) W_{2}+b W_{3}+g W_{5}=1 \\
& \left(\frac{m}{n}\right) W_{2}+c W_{3}+h W_{5}=1 \\
& W_{1}+W_{2}+W_{3}=1
\end{aligned}
$$

Solving equations (3-41), (3-42) and (3-43) together for $W_{1}, W_{2}$ and $W_{3}$ in terms of $W_{5}$ will lead to following equations,

$$
\begin{aligned}
& W_{1}=C_{151}+C_{152} W_{5} \\
& W_{2}=C_{251}+C_{252} W_{5} \\
& W_{3}=C_{351}+C_{352} W_{5}
\end{aligned}
$$

Where,

$$
\begin{aligned}
& C_{351}=\frac{m-1}{m b-c} \text { and } C_{352}=\frac{h-m g}{m b-c} \\
& C_{251}=\frac{n *(c-b)}{c-m b} \text { and } C_{252}=\frac{n *(h b-g c)}{c-m b} \\
& C_{151}=1-\left(C_{251}+C_{351}\right) \text { and } C_{152}=C_{252}+C_{352}
\end{aligned}
$$


Now the dual objective function can be written in terms of $W_{5}$ as,

$$
Z=\left(\frac{C_{1}}{C_{151}-C_{152} W_{5}}\right)^{C_{151}-C_{152} W_{5}}\left(\frac{C_{2}}{C_{251}+C_{252} W_{5}}\right)^{C_{251}+C_{252} W_{5}}\left(\frac{C_{3}}{C_{351}+C_{352} W_{5}}\right)^{C_{351}+C_{352} W_{5}}\left(C_{s}^{\prime}\right)^{W_{5}}
$$

Taking the natural $\log$ on both the sides of this equation will lead to the following expression,

$$
\ln (Z)=\left\{\begin{array}{l}
\left(C_{151}-C_{152} W_{5}\right) * \ln \left(\frac{C_{1}}{C_{151}-C_{152} W_{5}}\right) \\
+\left(C_{251}+C_{252} W_{5}\right) * \ln \left(\frac{C_{2}}{C_{251}+C_{252} W_{5}}\right) \\
+\left(C_{351}+C_{352} W_{5}\right) * \ln \left(\frac{C_{3}}{C_{351}+C_{352} W_{5}}\right)+W_{5} * \ln \left(C_{s}^{\prime}\right)
\end{array}\right\}
$$

This simplifies to,

$$
\ln (Z)=\left\{\begin{array}{l}
\left(C_{151} \ln C_{1}+C_{251} \ln C_{2}+C_{351} \ln C_{3}\right) \\
+\left(-C_{152} \ln C_{1}+C_{252} \ln C_{2}+C_{352} \ln C_{3}+\ln C_{s^{\prime}}\right) * W_{5} \\
-C_{151} \ln \left(C_{151}-C_{152} W_{5}\right)-C_{251} \ln \left(C_{251}+C_{252} W_{5}\right) \\
-C_{351} \ln \left(C_{351}+C_{352} W_{5}\right)+C_{152} * W_{5} * \ln \left(C_{151}-C_{152} W_{5}\right) \\
-C_{252} * W_{5} * \ln \left(C_{251}+C_{252} W_{5}\right)-C_{352} * W_{5} * \ln \left(C_{351}+C_{352} W_{5}\right)
\end{array}\right\}
$$

It may be noted that equation (3-52) can be solved using a search techniques e.g. Dicotomic search, Fibonacci search, Golden section search, Lattice search etc. Alternatively, since the only variable in this model is $W_{5}$, the optimal value of $W_{5}$ can be obtained by taking the derivative of the preceding term with respect to $W_{5}$ and equating it to zero (equations 3-53 and 3-54).

$$
\frac{\partial \ln (Z)}{\partial W_{5}} \quad=0
$$


Or,

$$
\left\{\begin{array}{l}
\left(-C_{152} \ln C_{1}+C_{252} \ln C_{2}+C_{352} \ln C_{3}+\ln C_{s^{\prime}}\right) \\
+\left(\frac{C_{151} C_{152}}{C_{151}-C_{152} W_{5}}\right)-\left(\frac{C_{251} C_{252}}{C_{251}+C_{252} W_{5}}\right)-\left(\frac{C_{351} C_{352}}{C_{351}+C_{352} W_{5}}\right) \\
+C_{152}\left(\frac{-C_{152} W_{5}}{C_{151}-C_{152} W_{5}}+\ln \left(C_{151}-C_{152} W_{5}\right)\right) \\
-C_{252}\left(\frac{C_{252} W_{5}}{C_{251}+C_{252} W_{5}}+\ln \left(C_{251}+C_{252} W_{5}\right)\right) \\
-C_{352}\left(\frac{C_{352} W_{5}}{C_{351}+C_{352} W_{5}}+\ln \left(C_{351}+C_{352} W_{5}\right)\right)
\end{array}\right\}=0
$$

It may be verified that the second derivative of the preceding expression will result into a negative value. To ensure this property, the function was plotted with changing values of different parameters in the model and the proposed model was able to find the optimum (maximum) solution in each case. An example plot between the dual variable $W_{5}$ and the corresponding dual objective function value is given in Figure 3.1.

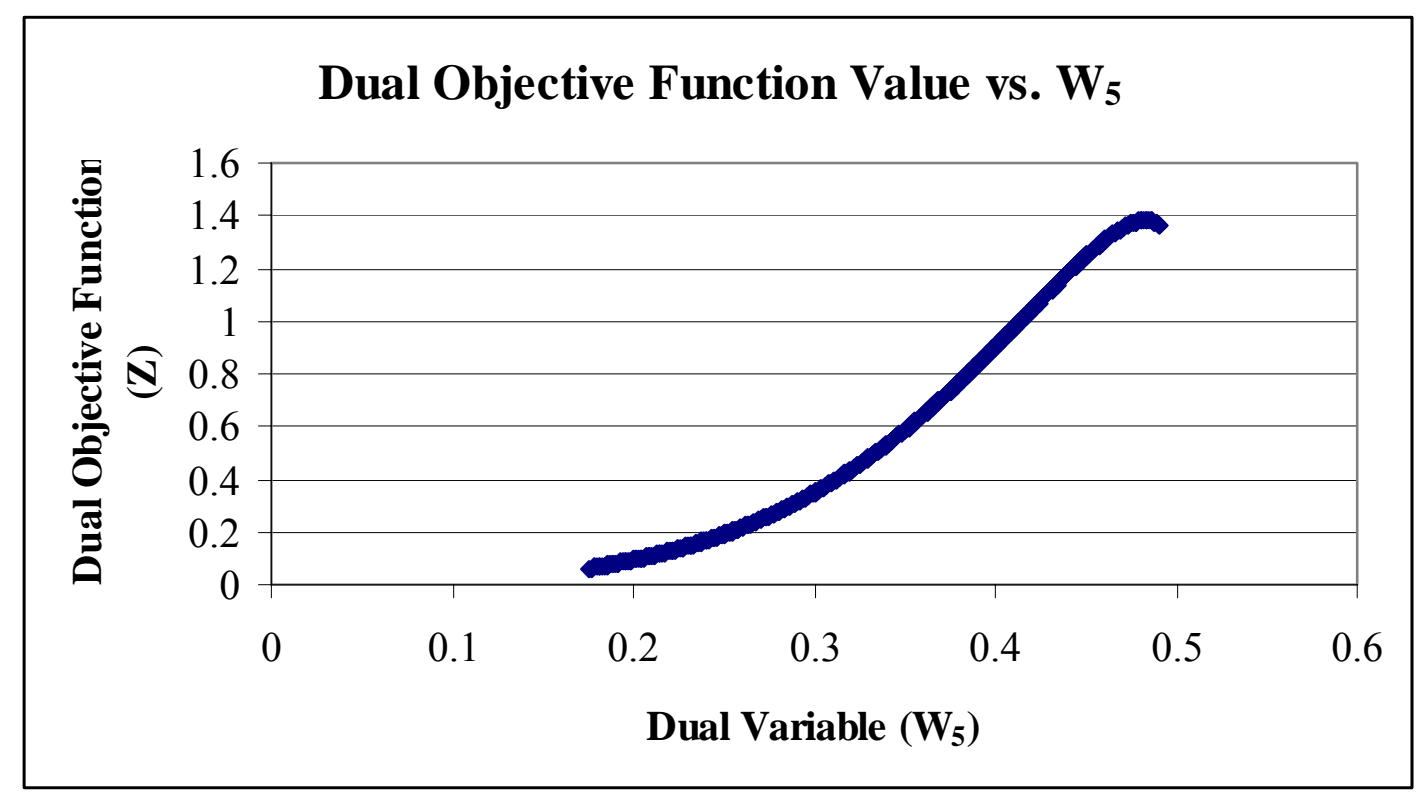

Figure 3.1: Plot of dual objective function value vs. dual variable value 
It may be noted that the function is feasible only for certain values of the dual variable $W_{5}$, therefore the curve is plotted for the feasible range only. Also, the resulting curve is concave and has only one maximum. This means that the value of $W_{5}$ obtained from the first derivative equation will get the maximum value for the original expression. This gives the value that maximizes $Z$ or minimizes the total machining cost which includes the cost of electrical energy.

\subsection{Derivation of Primal Solution from Dual Solution}

Once the values of all the dual variables known, it is necessary to translate these values into meaningful primal variables' values. To calculate the values for the primal variables, the relationship between geometric programming primal and dual formulation is used. As defined in Section 3.4, the relationships are given as,

$$
\begin{array}{lllll}
C_{1} V^{-1} f^{-1} & =W_{1} C_{u} & \text { or } & V^{-1} f^{-1} & =\frac{W_{1} C_{u}}{C_{1}} \\
C_{2} V^{\frac{1}{n}-1} f^{\frac{m}{n}-1} & =W_{2} C_{u} & \text { or } & V^{\frac{1}{n}-1} f^{\frac{m}{n}-1} & =\frac{W_{2} C_{u}}{C_{2}} \\
C_{3} V^{b-1} f^{c-1} & =W_{3} C_{u} & \text { or } & V^{b-1} f^{c-1} & =\frac{W_{3} C_{u}}{C_{3}} \\
C_{s}^{\prime} V^{g} f^{h} & =1 & \text { or } & V^{g} f^{h}=\frac{1}{C_{s}^{\prime}}
\end{array}
$$

Now, the ratio of the first two relations and then the ratio of the first and the third relation can be written as,

$$
\begin{aligned}
V^{-\frac{1}{n}} f^{-\frac{m}{n}} & =\frac{W_{1} C_{2}}{W_{2} C_{1}} \\
V^{-b} f^{-c} & =\frac{W_{1} C_{3}}{W_{3} C_{1}}
\end{aligned}
$$


Taking the natural log on both the side of these equations and rearranging the terms, the following relationship can be developed.

$$
\begin{array}{lll}
\ln V+m * \ln f & =-n * \ln \left(\frac{W_{1} * C_{2}}{W_{2} * C_{1}}\right) \\
b^{*} \ln V+c * \ln f & = & -\ln \left(\frac{W_{1} * C_{3}}{W_{3} * C_{1}}\right)
\end{array}
$$

Solving these two equations together gives the value of $V$ and $f$ as follows,

$$
f=\exp \left[\left(\frac{1}{m b-c}\right) *\left\{\ln \left(\frac{W_{1} * C_{3}}{W_{3} * C_{1}}\right)-n * b * \ln \left(\frac{W_{1} * C_{2}}{W_{2} * C_{1}}\right)\right\}\right]
$$

and,

$$
V=\exp \left[\left(-\frac{1}{b}\right) *\left\{\ln \left(\frac{W_{1} * C_{3}}{W_{3} * C_{1}}\right)+c * \ln f\right\}\right]
$$

\subsection{Computer Model Development}

It is evident that it is hard to get a direct expression for $W_{5}$ from equation (3-54) though it may be possible. For simplicity, a search algorithm may be used to find the value for $W_{5}$. At the same time, the values of the dual variables should be non-negative so the search is restricted to non-negative values only. The model has been developed using VBA (visual basic) interface in Microsoft Excel ${ }^{\circledR}$. The model has been developed in Microsoft Excel ${ }^{\circledR}$ since it is readily available in almost all the plants.

The model has a user interface to get all the input values and then perform the necessary calculations to find the optimal machining parameters.

A general guideline of the different steps in the model is as follows:

1. The input values for all the parameters (b, c, e, n, m, p, g, h, I, $\mathrm{C}_{\mathrm{m}}, \mathrm{C}_{\mathrm{s}}, \mathrm{HP}_{\max }$, $\mathrm{SF}_{\max }, \mathrm{C}, \mathrm{d}, \mathrm{L}_{\mathrm{n}}$, Dia, Tool change time, Tool cost, Labor rate, $\$ / \mathrm{kWh}, \$ / \mathrm{kW}$, Batch size) are provided by the user. 
2. The model calculates the parameter necessary for the existing mathematical model based on the input given by the user.

3. The model performs the first iteration and calculates the optimal solution as per the existing mathematical model.

4. Once again, based on the user input in step 1, the model calculates the necessary parameters for the proposed model. To start the calculations for the proposed model, it considers the current efficiency of the motor as the one calculated with respect to the load factor of the motor based on the existing model's optimal machining parameters.

5. The model performs a new iteration, and gets the optimal cutting parameters based on the assumed load factor of the motor.

6. If the load factor with respect to the proposed machining parameters is same or close to the one assumed, go to step 8 otherwise go to step 7.

7. Set the assumed load factor as the proposed load factor and calculate the motor efficiency for this load. Go back to step 5.

8. Display the results and stop.

A flow chart for the computer based model is given in Figure 3.2. The computer model's input and the results screens are shown in Figure 3.3 and Figure 3.4.

\subsection{Conclusion}

In this chapter, the mathematical model was developed with energy cost components as an integral part of the optimization process. The model was formulated as a geometric programming problem and the corresponding dual problem was developed and used to design the solution procedure. A computer model was designed to automate the process of the search algorithm to find the optimal solution for machining parameters. 


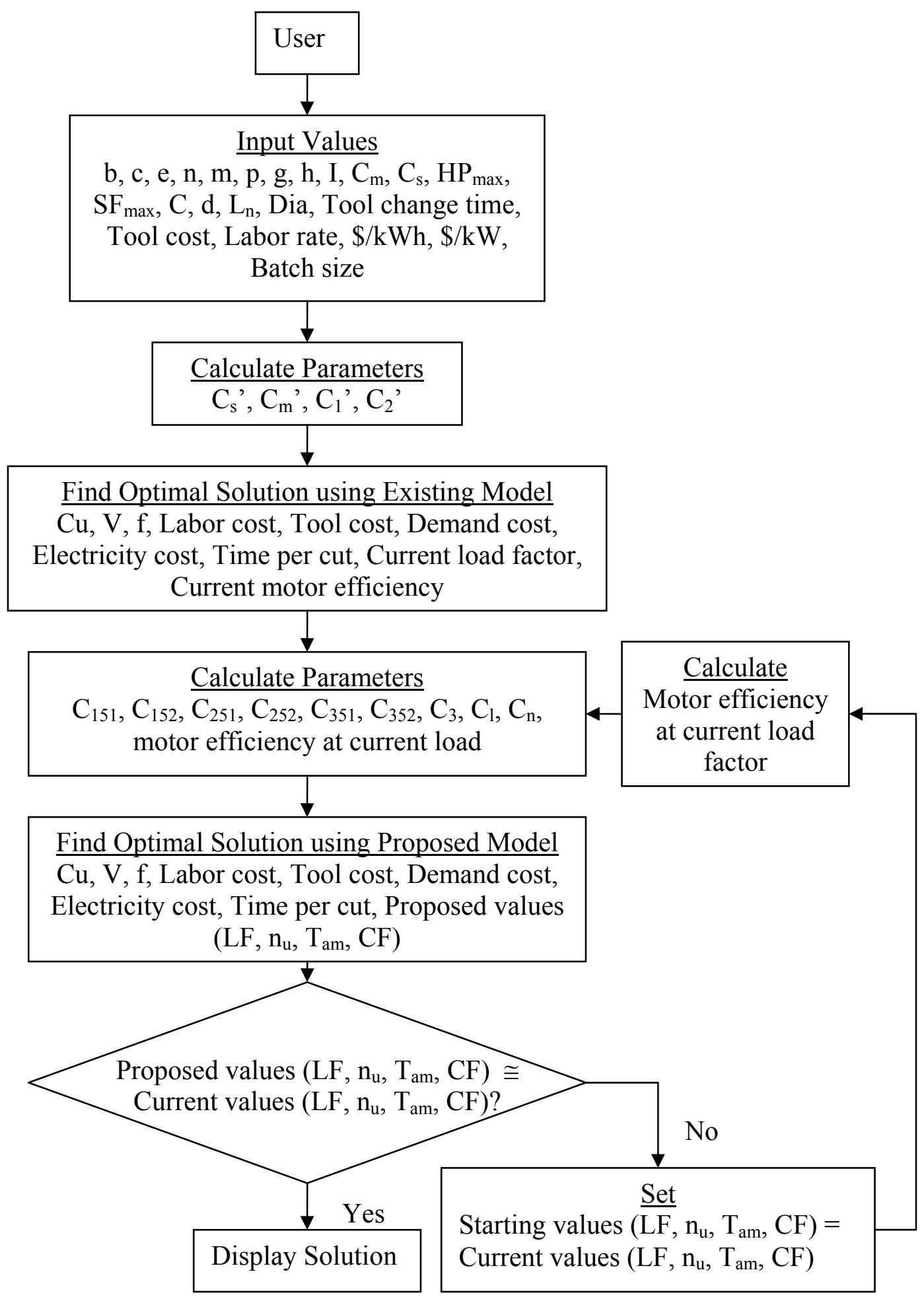

Figure 3.2: Flow chart for the computer model 


\begin{tabular}{|c|c|c|c|c|c|}
\hline \multicolumn{6}{|c|}{ Calculation of cutting parameters, $v, f, C u$ for optimal solution } \\
\hline \multicolumn{2}{|c|}{ Exponents in machine power constraint } & \multicolumn{2}{|c|}{ Exponents in the tool life equation } & \multicolumn{2}{|c|}{ Exponents in surface finish constraint } \\
\hline $\mathrm{b}$ & 0.91 & $n$ & 0.25 & $\mathrm{~g}$ & -1.52 \\
\hline $\mathrm{c}$ & 0.78 & $\mathrm{~m}$ & 0.29 & $\mathrm{~h}$ & 1.004 \\
\hline $\mathrm{e}$ & 0.75 & $p$ & 0.35 & I & 0.25 \\
\hline \multicolumn{2}{|c|}{ Coefficients in constraints of } & \multicolumn{2}{|c|}{ Tool parameters } & \multicolumn{2}{|c|}{ Maximum } \\
\hline Mic Power $\mathrm{C}_{\mathrm{m}}$ & 2.394 & Tool change time $(\min )=$ & 0.5 & $\begin{array}{c}\text { M/c power available } \\
\text { HPmax (HP) } \\
\end{array}$ & 4 \\
\hline Surface finish $\mathrm{C}_{s}$ & 204.62 & Tool cost $(\$ /$ change $)=$ & 0.5 & $\begin{array}{l}\text { Surface finish acceptable } \\
\text { Sfmax (in) }\end{array}$ & $5.00 \mathrm{E}-05$ \\
\hline & & Labor rate $(\$ / \mathrm{min})=$ & 0.1 & & \\
\hline \multicolumn{2}{|c|}{ Rapid traverse values } & Tool Life Constant $(C)=$ & 80 & \multicolumn{2}{|c|}{ Energy charges } \\
\hline Time required (min/pass) & 1 & Depth of cut (d), in. $=$ & 0.2 & Usage $(\$ / K W h)$ & 0.05 \\
\hline \multirow[t]{2}{*}{ Power required (KW) } & 1 & length of job $(\mathrm{Ln})$, in. = & 8 & Demand $(\$ / K W)$ & 10 \\
\hline & & Dia of the job (in.) $=$ & 6 & & \\
\hline \multicolumn{2}{|c|}{ Other time values per month (hours) } & \multicolumn{2}{|c|}{ Calculated parameters } & \multicolumn{2}{|c|}{ Machine setup } \\
\hline Total time & 240 & $\mathrm{Cs}^{\circ}$ & 2736752.824 & Time per unit (mins) & 1 \\
\hline Maintenance & 5 & $\mathrm{Cm}^{2}$ & 0.178993249 & & \\
\hline \multirow[t]{3}{*}{ Idle } & 30 & $\mathrm{C} 1$ & 1.256 & \multicolumn{2}{|c|}{ Time interval for demand cost } \\
\hline & & $\mathrm{C} 2{ }^{\prime}$ & $1.77188 \mathrm{E}-08$ & Interval (min.) & 15 \\
\hline & & \multicolumn{2}{|c|}{ Analyze } & & \\
\hline
\end{tabular}

Figure 3.3: Input module for the computer model 


\begin{tabular}{|c|c|c|c|c|c|}
\hline \multicolumn{6}{|c|}{ Optimal Solution } \\
\hline & Old parameters & (without energy) & New paramete & rs (with energy) & \% savings \\
\hline Cutting Cost $(\mathrm{Cu})$ & \begin{tabular}{|r|}
$\$ 1.38$ \\
\end{tabular} & & $\$ 1.38$ & & $0.00 \%$ \\
\hline Cutting Speed (V) & 433.25 & sfpm & 433.77 & sfpm & \\
\hline Cutting Feed (f) & 0.0038 & ipr & 0.0038 & ipr & \\
\hline Labor Cost & $\$ 0.76$ & & $\$ 0.76$ & & \\
\hline Tool Cost & $\$ 0.59$ & & $\$ 0.59$ & & \\
\hline Demand Cost & $\$ 0.02$ & & $\$ 0.02$ & & \\
\hline Electricity Cost & $\$ 0.01$ & & $\$ 0.01$ & & $0.00 \%$ \\
\hline Machining time (min.) & 7.62 & & 7.60 & & $0.30 \%$ \\
\hline Energy cost/total cost & $2.17 \%$ & & $2.17 \%$ & & \\
\hline
\end{tabular}

Figure 3.4: Results module for the computer model 


\section{Chapter 4}

\section{Model Validation and Sensitivity Analysis}

The proposed model was validated using example problems published in the literature. It may be noted that the current models do not have the energy cost component; therefore the values for speed and feed in the results were used to indirectly calculate the energy cost. After validation of the proposed model, extensive sensitive analysis was performed on different variables in the model.

\subsection{Model Validation}

Two example problems were taken for model validation. The problems were solved by different researchers, but the results are taken only from Ermer et al. [1981] and Tsai [1986].

\subsubsection{Example 1}

This example was published by Ermer et al. [1981]. The values used in the example problem are:

$\begin{array}{lll}\mathrm{b} & = & 0.91 \\ \mathrm{c} & = & 0.78 \\ \mathrm{e} & = & 0.75 \\ \mathrm{n} & = & 0.25 \\ \mathrm{~m} & = & 0.29 \\ \mathrm{p} & = & 0.35 \\ \mathrm{C} & = & 80 \\ \mathrm{~g} & = & -1.52 \\ \mathrm{~h} & = & 1.004 \\ \mathrm{i} & = & 0.25 \\ \mathrm{C}_{\mathrm{m}} & = & 2.394\end{array}$




$$
\begin{array}{lll}
\mathrm{C}_{\mathrm{s}} & = & 204.62 \\
\mathrm{HP}_{\text {max }} & = & 4 \\
\mathrm{SF}_{\max } & = & 50 \mu \mathrm{in} . \\
\mathrm{T}_{\text {cost }} & =\$ 0.5 / \text { edge } \\
\mathrm{T}_{\mathrm{c}} & =0.5 \mathrm{~min} \\
\mathrm{~d} & =0.2 \mathrm{in} . \\
\mathrm{D} & =6 \mathrm{in} . \\
1 & = & 8 \mathrm{in} . \\
\mathrm{L}_{\mathrm{r}} & =\$ 0.1 / \mathrm{min}
\end{array}
$$

The authors had constant setup time in the equation but the corresponding cost value is not considered here. The results presented by the authors are:

$$
\begin{array}{lll}
\mathrm{V} & =432 \mathrm{sfpm} \\
\mathrm{f} & = & 0.0038 \mathrm{ipr} \\
\text { Cost } & = & \$ 1.36 \text { (labor and tool cost only) }
\end{array}
$$

To calculate the cost of energy, the following parameters are assumed.

$$
\begin{array}{lll}
\mathrm{T}_{\mathrm{r}} & = & 1 \mathrm{~min} \\
\mathrm{DP}_{\mathrm{Tr}} & = & 1 \mathrm{~kW} \\
\mathrm{~T}_{\text {month }}= & 240 \text { hours } \\
\mathrm{T}_{\text {maint }}= & 5 \text { hours } \\
\mathrm{T}_{\text {idle }}= & 30 \text { hours } \\
\mathrm{ER} & =\$ 0.05 / \mathrm{kWh} \\
\mathrm{DR} & =\$ 10 / \mathrm{kW} \\
\mathrm{T}_{\mathrm{S}} & =1 \mathrm{~min} \\
\mathrm{~T}_{\mathrm{D}} & =15 \mathrm{~min}
\end{array}
$$

Based on these parameter values, the energy cost components and the total cost were calculated as,

$$
\begin{aligned}
& \mathrm{EC}=\$ 0.01 \\
& \mathrm{DC}=\$ 0.02
\end{aligned}
$$




$$
\begin{array}{rll}
\mathrm{C}_{\mathrm{u}} & = & \$ 1.36+\$ 0.01+\$ 0.02 \\
& = & \$ 1.39
\end{array}
$$

Now, based on the proposed model, the calculated values are:

$$
\begin{array}{lll}
\mathrm{V} & =433.77 \mathrm{sfpm} \\
\mathrm{f} & =0.0038 \mathrm{ipr} \\
\mathrm{LC} & =\$ 0.76 \\
\mathrm{TC} & =\$ 0.59 \\
\mathrm{EC} & =\$ 0.01 \\
\mathrm{DC} & =\$ 0.02 \\
\mathrm{C}_{\mathrm{u}} & =\$ 1.38
\end{array}
$$

Therefore, the savings from using the proposed model can be calculated as,

$$
\begin{array}{lll}
\text { Savings } & =(\text { Current }- \text { proposed }) * 100 / \text { Current } \\
& =(\$ 1.39-\$ 1.38)^{*} 100 / \$ 1.39 \\
& =0.72 \%
\end{array}
$$

The other interesting results that should be noted here is the difference in machining time and the total energy cost. The values from the current and proposed models are calculated as,

\section{Current model}

$$
\mathrm{T}_{\mathrm{m}}=7.65 \mathrm{~min}
$$

\section{Proposed model}

$$
\mathrm{T}_{\mathrm{m}} \quad=\quad 7.60 \mathrm{~min}
$$

It may be noted that the machining time is reduced by $0.70 \%$. It is worth mentioning that even though the total cost is reduced by only $0.72 \%$, the reduction in machining time by $0.70 \%$ is worth the effort because of increased production capacity and less overhead rate per unit. 


\subsubsection{Example 2}

This example is taken from Tsai [1986]. He has taken the example problem from Ermer et al. [1981] and the results presented by the author are as follows:

$$
\begin{array}{lll}
\mathrm{V} & = & 433.247 \mathrm{sfpm} \\
\mathrm{f} & = & 0.003804 \mathrm{ipr} \\
\text { Cost } & = & \$ 1.3530 \text { (labor cost and tool cost only) } \\
\mathrm{C}_{\mathrm{u}} & =\$ 1.3830
\end{array}
$$

Therefore, the savings can be calculated as,

$$
\begin{array}{lll}
\text { Savings } & = & (\text { Current }- \text { proposed }) * 100 / \text { Current } \\
& = & (\$ 1.3830-\$ 1.3829) * 100 / \$ 1.3830 \\
& =0.01 \%
\end{array}
$$

The machining times are calculated as,

\section{Current model}

$$
\mathrm{T}_{\mathrm{m}}=7.62 \mathrm{~min}
$$

\section{Proposed model}

$$
\mathrm{T}_{\mathrm{m}}=7.60 \mathrm{~min}
$$

Again, it can be shown that the machining time is reduced by $0.33 \%$, which results in increased production capacity and less overhead cost per unit produced.

\subsubsection{Example 3}

This example is taken from Tsai [1986]. This example was published by Ermer et al. [1981]. The values used in the example problem were same as given in example 1 except the following:

$$
\begin{array}{lll}
\mathrm{SF}_{\max } & = & 200 \mu \mathrm{in} . \\
\mathrm{d} & = & 0.15 \mathrm{in} .
\end{array}
$$


The results presented by the author are,

$$
\begin{array}{lll}
\mathrm{V} & = & 346.743 \mathrm{sfpm} \\
\mathrm{f} & = & 0.0116 \mathrm{ipr} \\
\text { Cost } & = & \$ 0.5543 \text { (labor and tool cost only) }
\end{array}
$$

Based on the other parameters, the energy and demand cost are calculated as,

$$
\begin{aligned}
& \mathrm{DC}=\$ 0.0126 \\
& \mathrm{EC}=\$ 0.0088 \\
& \mathrm{C}_{\mathrm{u}}=\$ 0.5757
\end{aligned}
$$

Now, based on the proposed model, the calculated values are:

$$
\begin{array}{lll}
\mathrm{V} & = & 347.438 \mathrm{sfpm} \\
\mathrm{f} & =0.0116 \mathrm{ipr} \\
\mathrm{LC} & =\$ 0.3106 \\
\mathrm{TC} & =\$ 0.2436 \\
\mathrm{EC} & =\$ 0.0088 \\
\mathrm{DC} & =\$ 0.0126 \\
\mathrm{C}_{\mathrm{u}} & =\$ 0.5756
\end{array}
$$

Therefore, the savings can be calculated as,

$$
\begin{array}{lll}
\text { Savings } & = & (\text { Current }- \text { proposed }) * 100 / \text { Current } \\
& = & (\$ 0.5757-\$ 0.5756) * 100 / \$ 0.5757 \\
& =0.02 \%
\end{array}
$$

The machining times are calculated as,

\section{Current model}

$$
\mathrm{T}_{\mathrm{m}}=3.12 \mathrm{~min}
$$

Proposed model

$$
\mathrm{T}_{\mathrm{m}}=3.11 \mathrm{~min}
$$

Again, it can be shown that the machining time is reduced by $0.54 \%$. 


\subsection{Sensitivity Analysis}

A sensitivity analysis was performed with respect to the parameters used in the proposed model. For most of the analysis, only one variable is changed at a time. The parameters used in the model were adopted from the example problem 1. Also, for each of the analysis performed in the following sections, the results are compared with the results obtained through the model proposed by Gopalakrishnan et al. [1991] and are given as percentage cost and time savings.

\subsubsection{Effect of Labor cost}

For this analysis, labor rate was changed from $\$ 0.10 /$ minute to $\$ 0.60 /$ minute in steps of $\$ 0.10$. The results are presented in the following figures. It may be noted that the percentage savings in the total cost is insignificant and decrease with an increase in the labor rate (Figure 4.1) and approaches to zero (no cost savings).

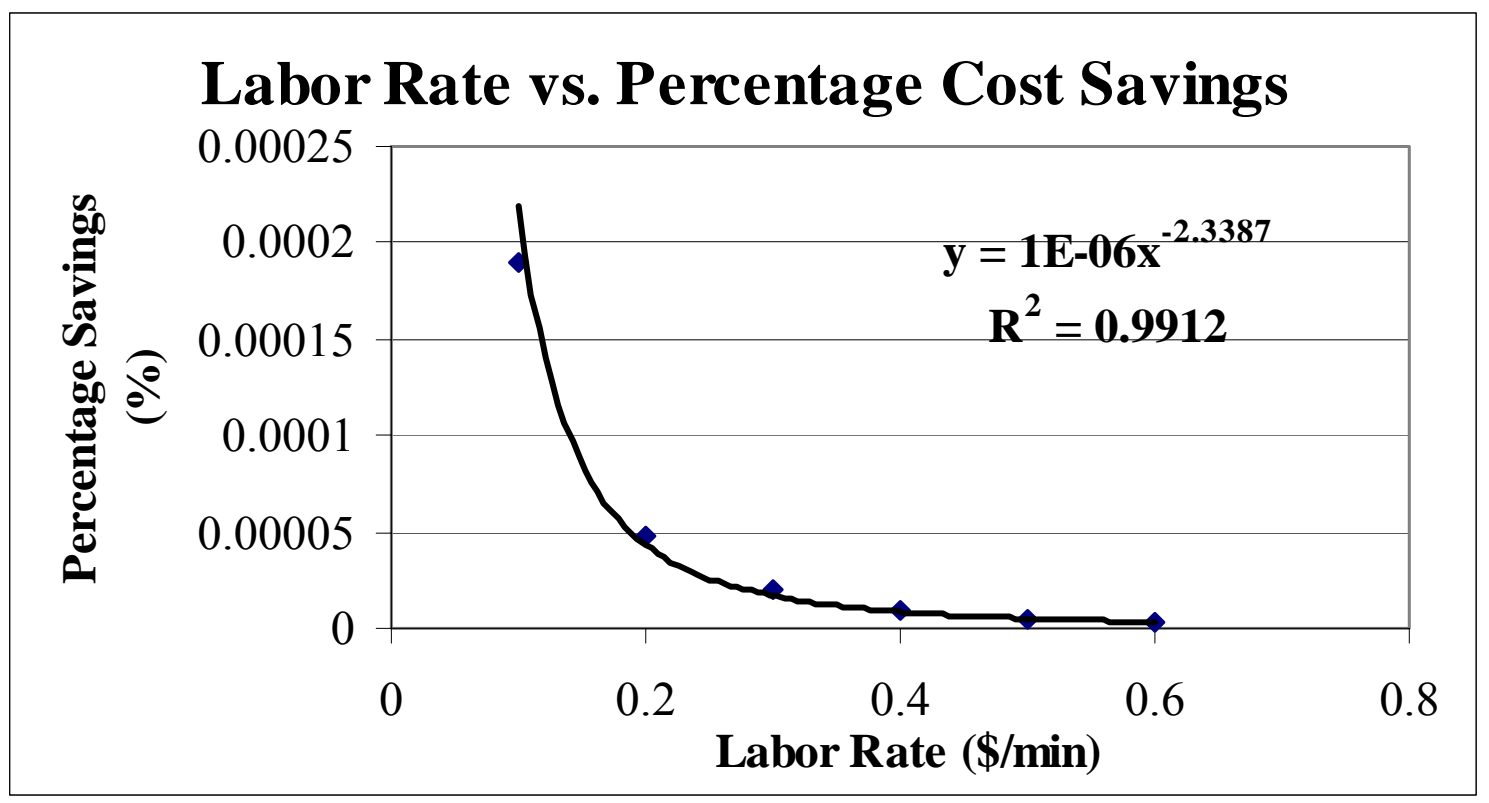

Figure 4.1: Effect of labor rate on percentage cost savings

Percentage time savings also decrease with an increase in the labor rate (Figure 4.2). Even though the percentage savings decrease with an increase in the labor rate, the 
proposed model always results in values that reduce the cutting cost with the energy cost components and increases the throughput of the system.

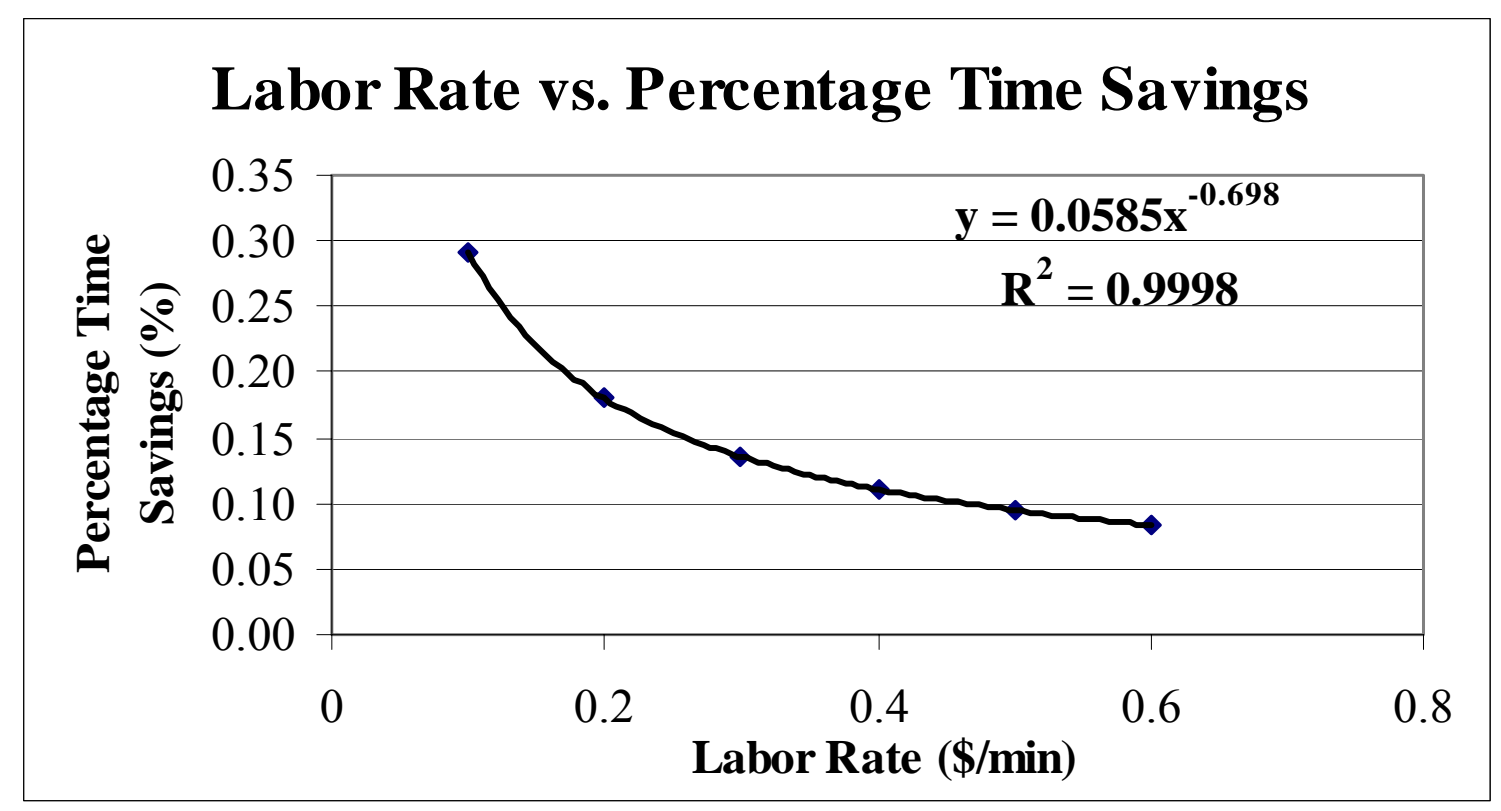

Figure 4.2: Effect of labor rate on percentage time savings

\subsubsection{Effect of Tool Constant}

In this case, the values were again taken as same as in Section 4.2.1 and the tool life constant was changed from 60 to 100 in steps of 5. The results from this analysis are shown in the following figures. It is observed that the percentage cost savings increase with an increase in the tool constant but start decreasing after some time (Figure 4.3). As shown in the figure for the percentage time savings (Figure 4.4), the savings increase with an increase in the tool life constant. This is possible because the higher tool life constant reduces the effective cost of the tool and therefore the importance of energy cost is increased. It may be pointed at this time that with advancement in the technology i.e. with better tools, the proposed model may be really helpful to increase the profit margin of the companies by increasing the production capacity with the same machine. 


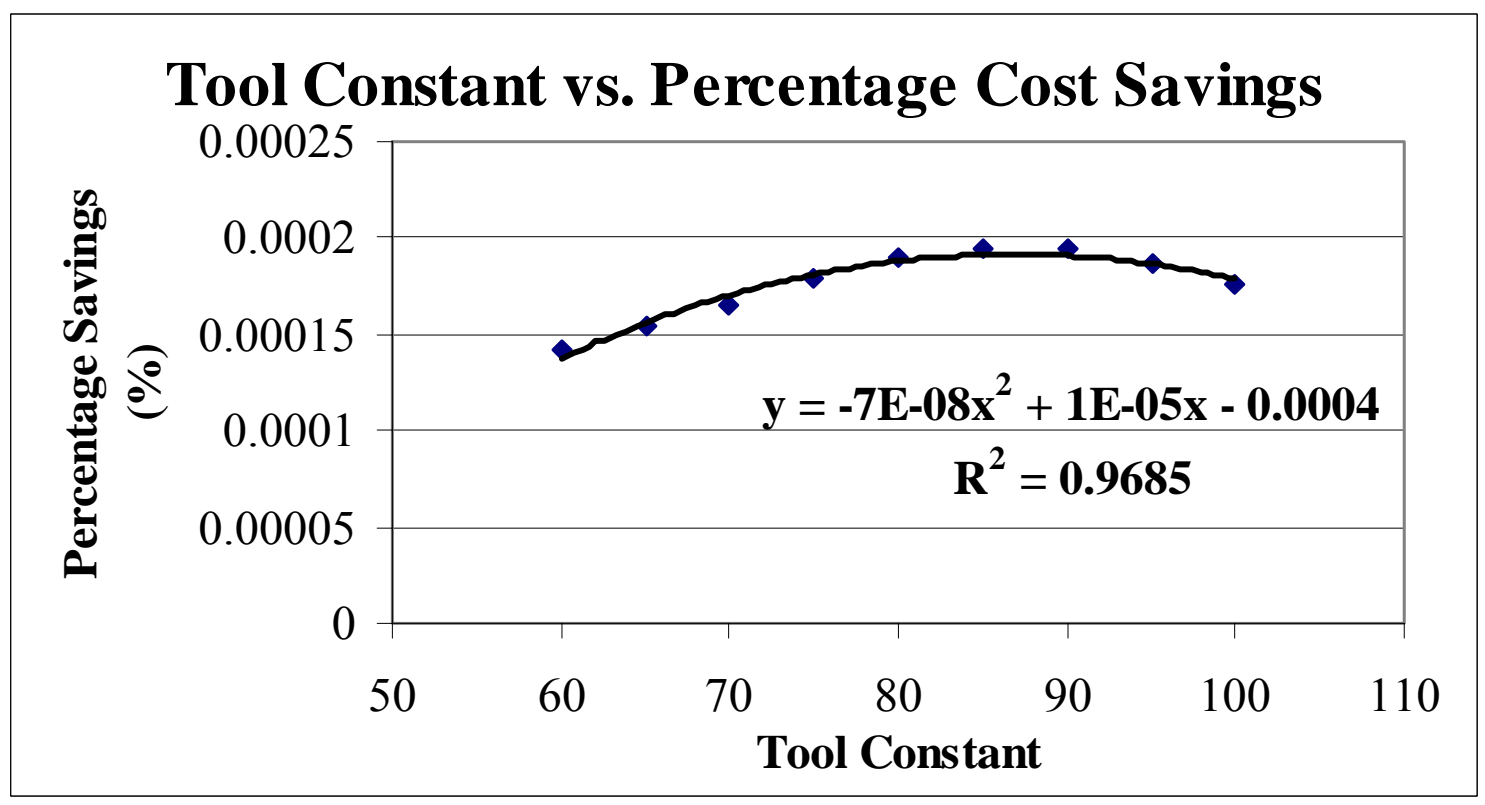

Figure 4.3: Effect of tool constant on percentage cost savings

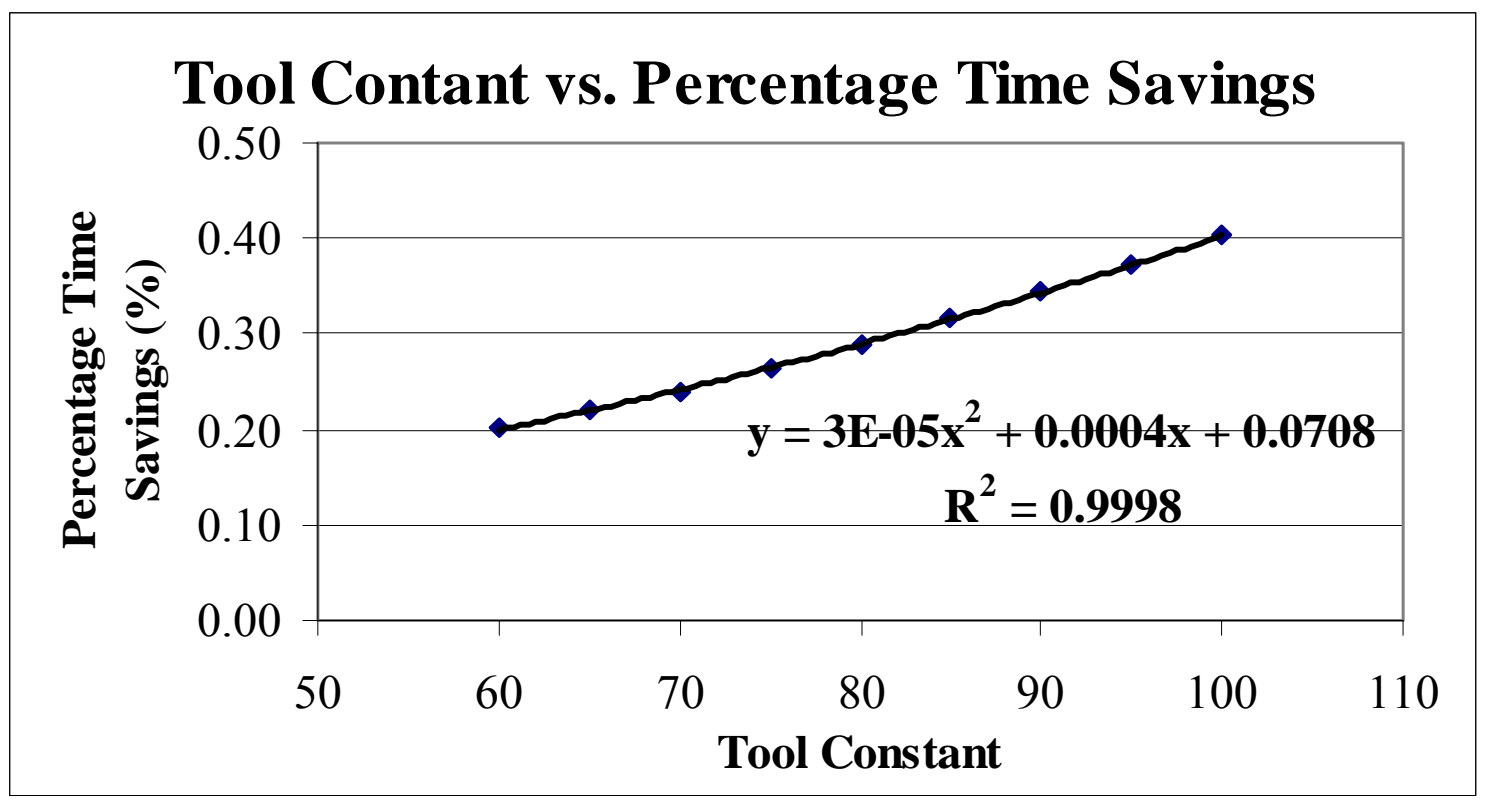

Figure 4.4: Effect of tool constant on percentage time savings 


\subsubsection{Effect of Unit Demand Cost}

For the sensitivity analysis with respect to the demand cost, the unit demand cost $(\$ / \mathrm{kW})$ was changed from $\$ 6 / \mathrm{kW}$ to $\$ 15 / \mathrm{kW}$ in the steps of $\$ 1 / \mathrm{kW}$. The results from this analysis are shown in the following figures.

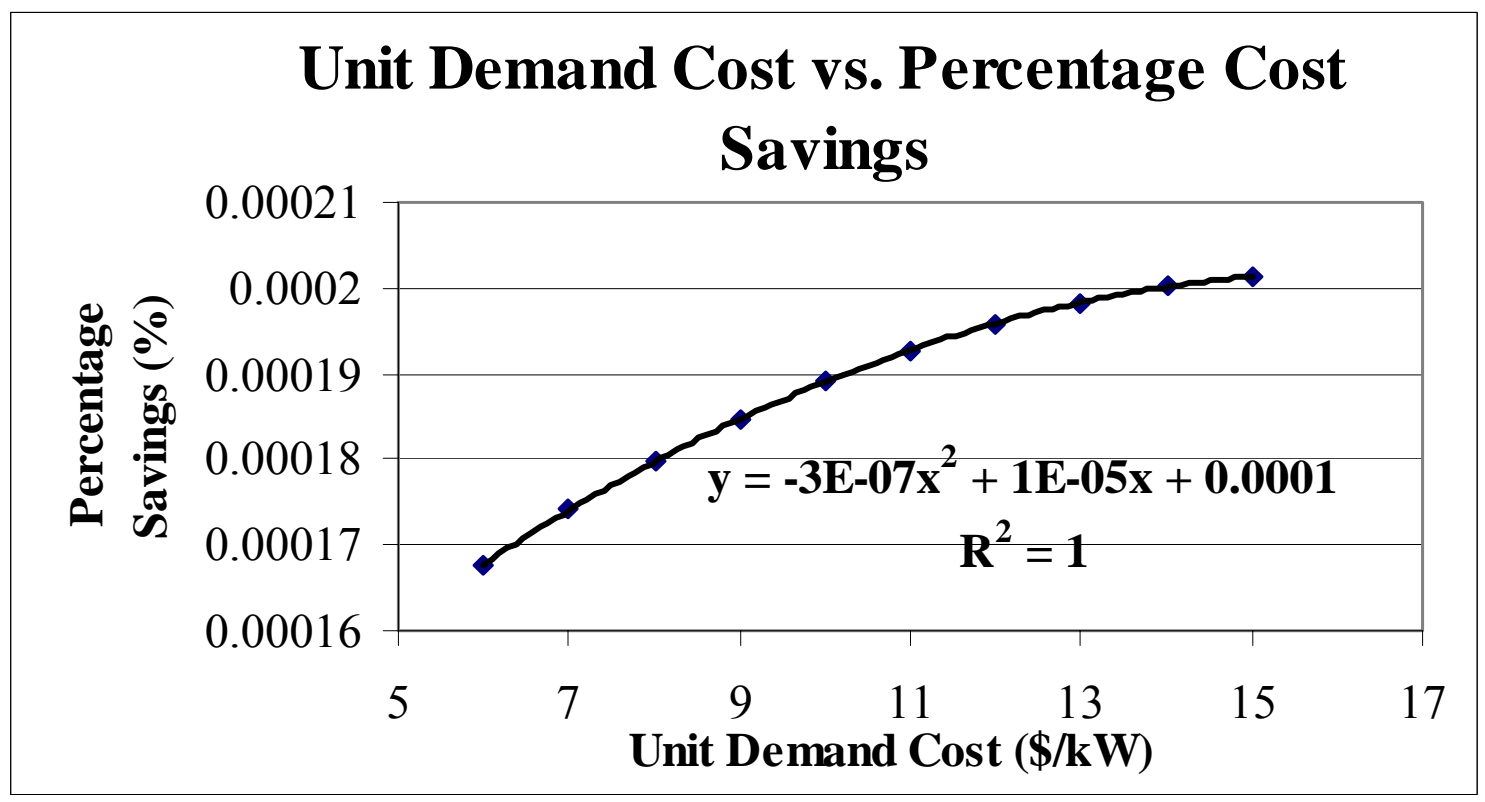

Figure 4.5: Effect of unit demand cost on percentage cost savings

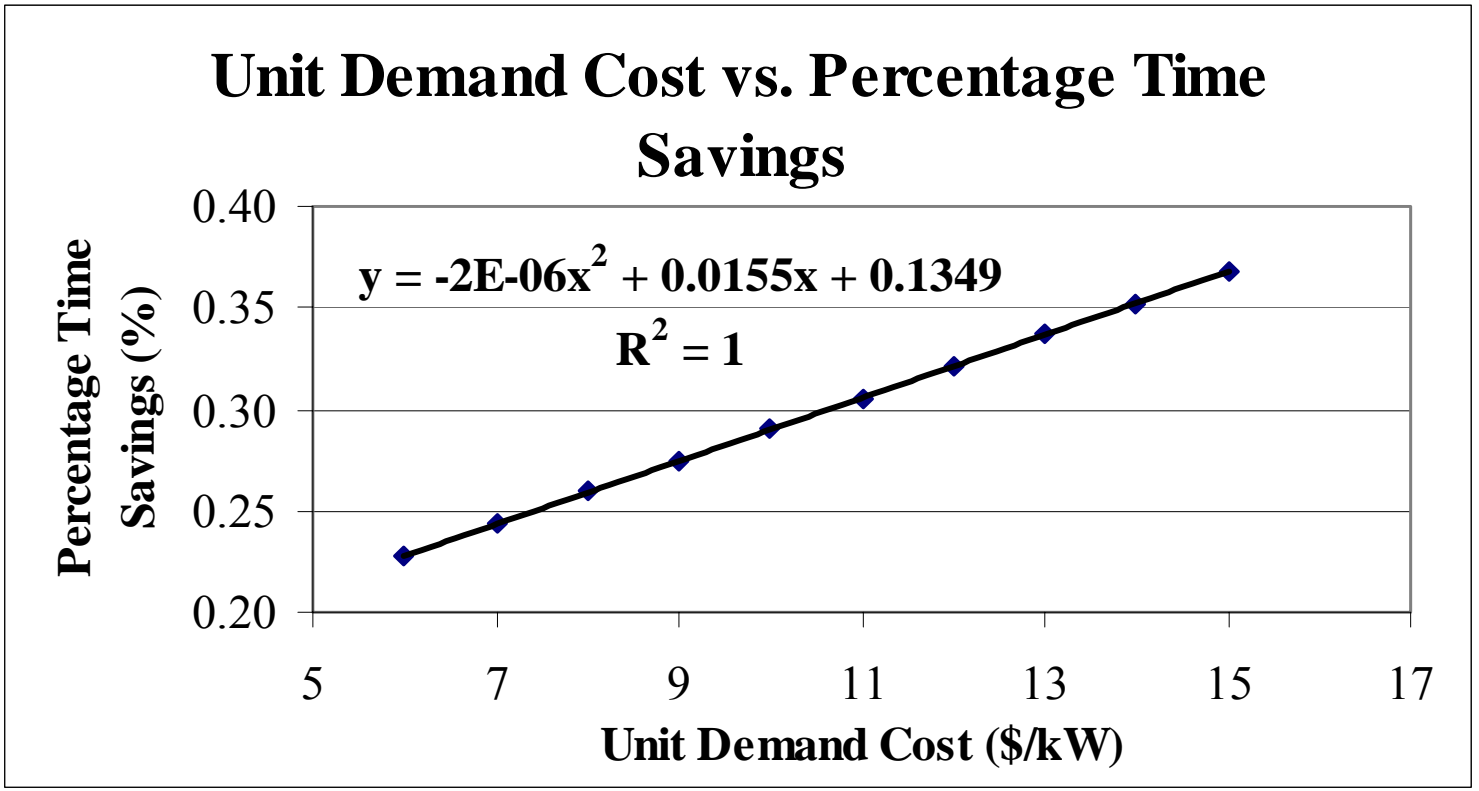

Figure 4.6: Effect of unit demand cost on percentage time savings 
From the plot of percentage cost savings, it is obvious that the savings increase with the increases in the demand rate. It can be seen that the percentage time savings increase almost linearly with increase in the demand cost.

\subsubsection{Effect of Unit Energy Usage Rate}

For the sensitivity analysis with respect to the usage rate, the unit energy cost $(\$ / \mathrm{kWh})$ was changed from $\$ 0.03 / \mathrm{kWh}$ to $\$ 0.12 / \mathrm{kWh}$ in the steps of $\$ 0.01 / \mathrm{kWh}$. The results from this analysis are shown in the following figures.

With an increase in the energy usage rate, the percentage savings increase and the proposed model always results in a better cost than current model values. Again, the cost savings are insignificant as compared to the current results. The percentage time savings increase with increase in the usage rate. This increase is explained by the energy cost term which is dependent on the machining time. To minimize the total cost which includes the cost of energy, the machining process should be performed at a faster rate.

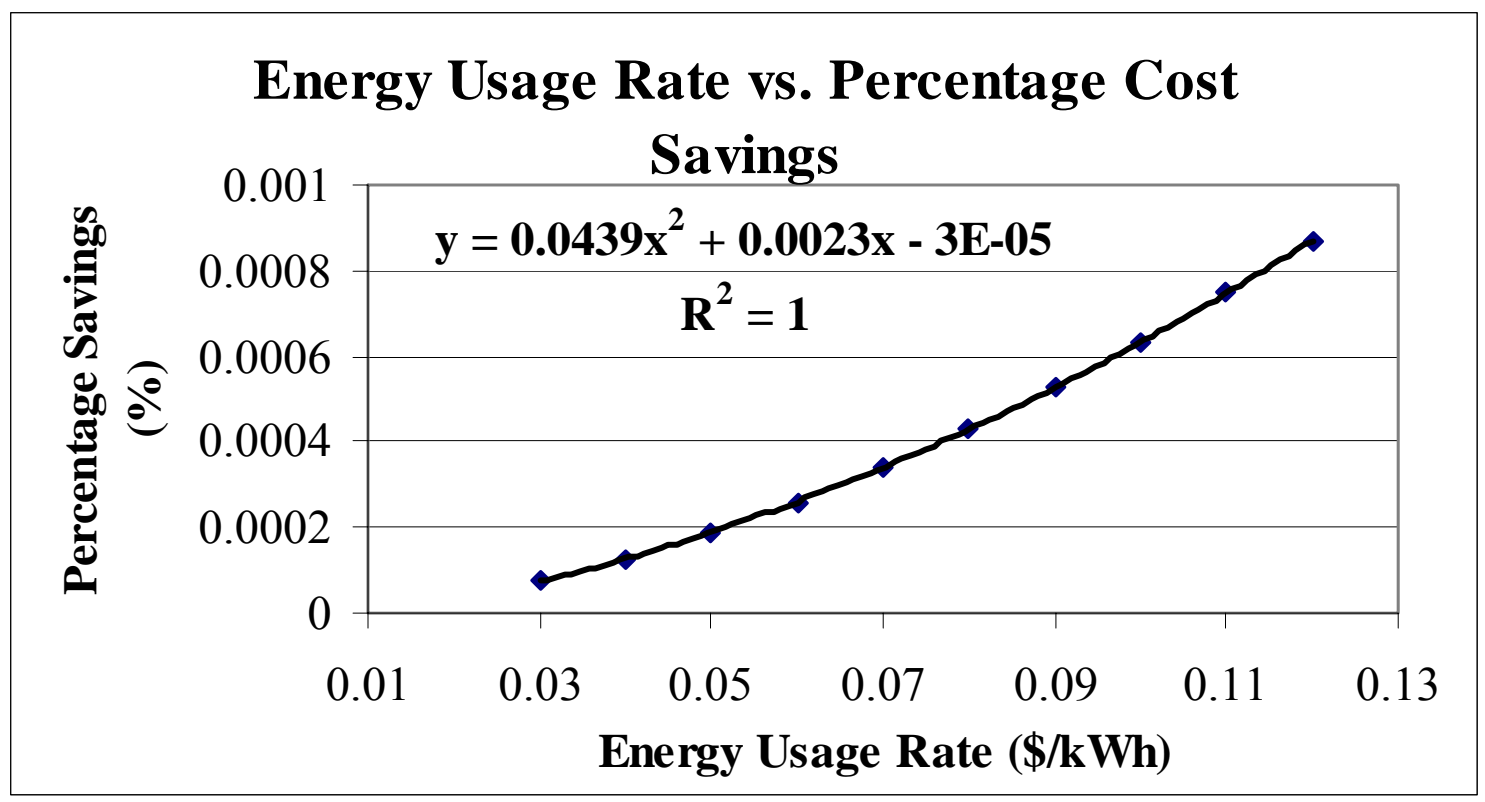

Figure 4.7: Effect of energy usage rate on percentage cost savings 


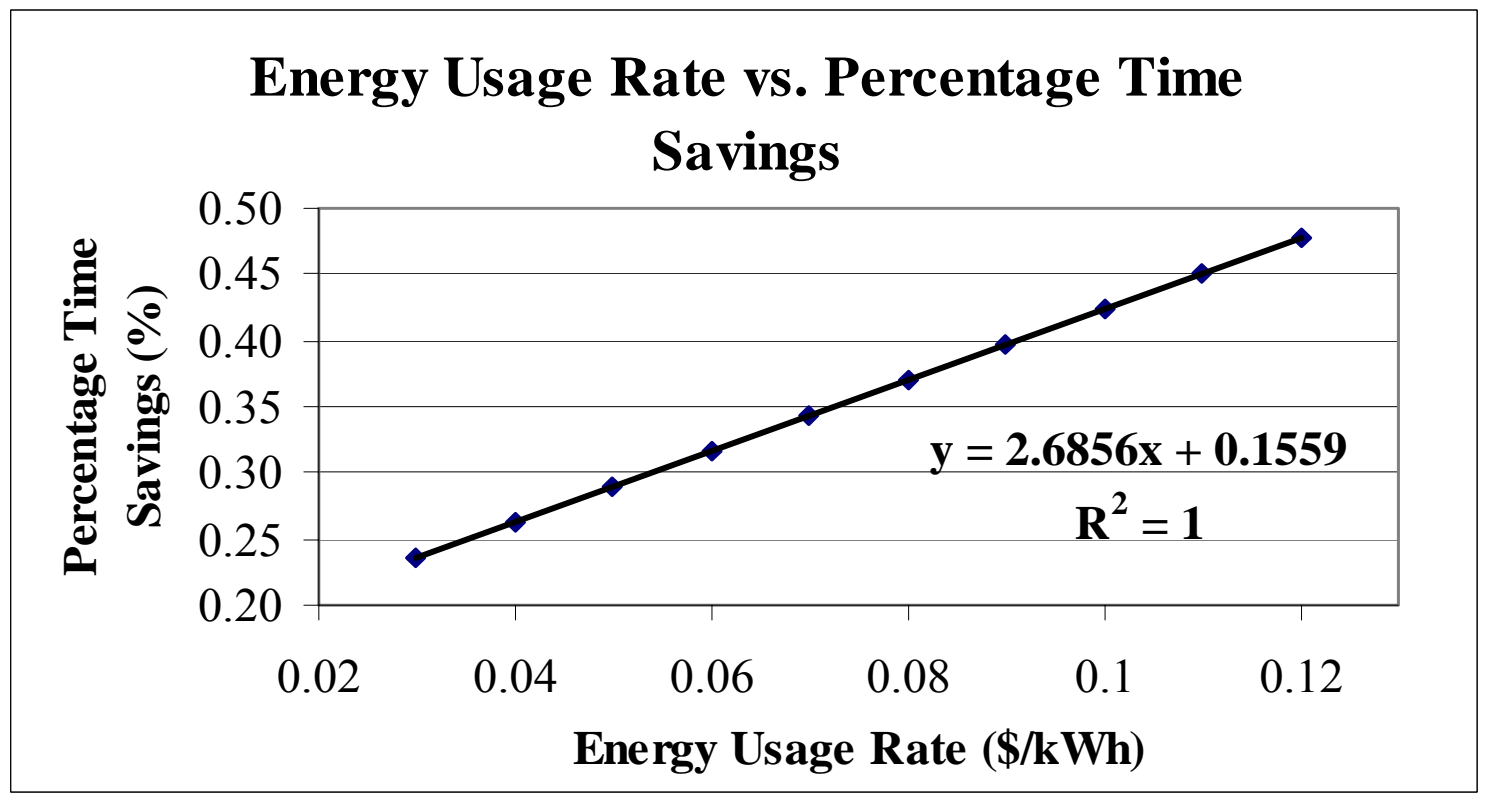

Figure 4.8: Effect of energy usage rate on percentage time savings

\subsubsection{Effect of Surface Finish Constraint}

For the sensitivity analysis with respect to the surface finish requirement, the value of maximum surface finish is changed from 70 micro inches to 250 micro inches in steps of 20 micro inches. The results from this analysis are shown in the following figures.

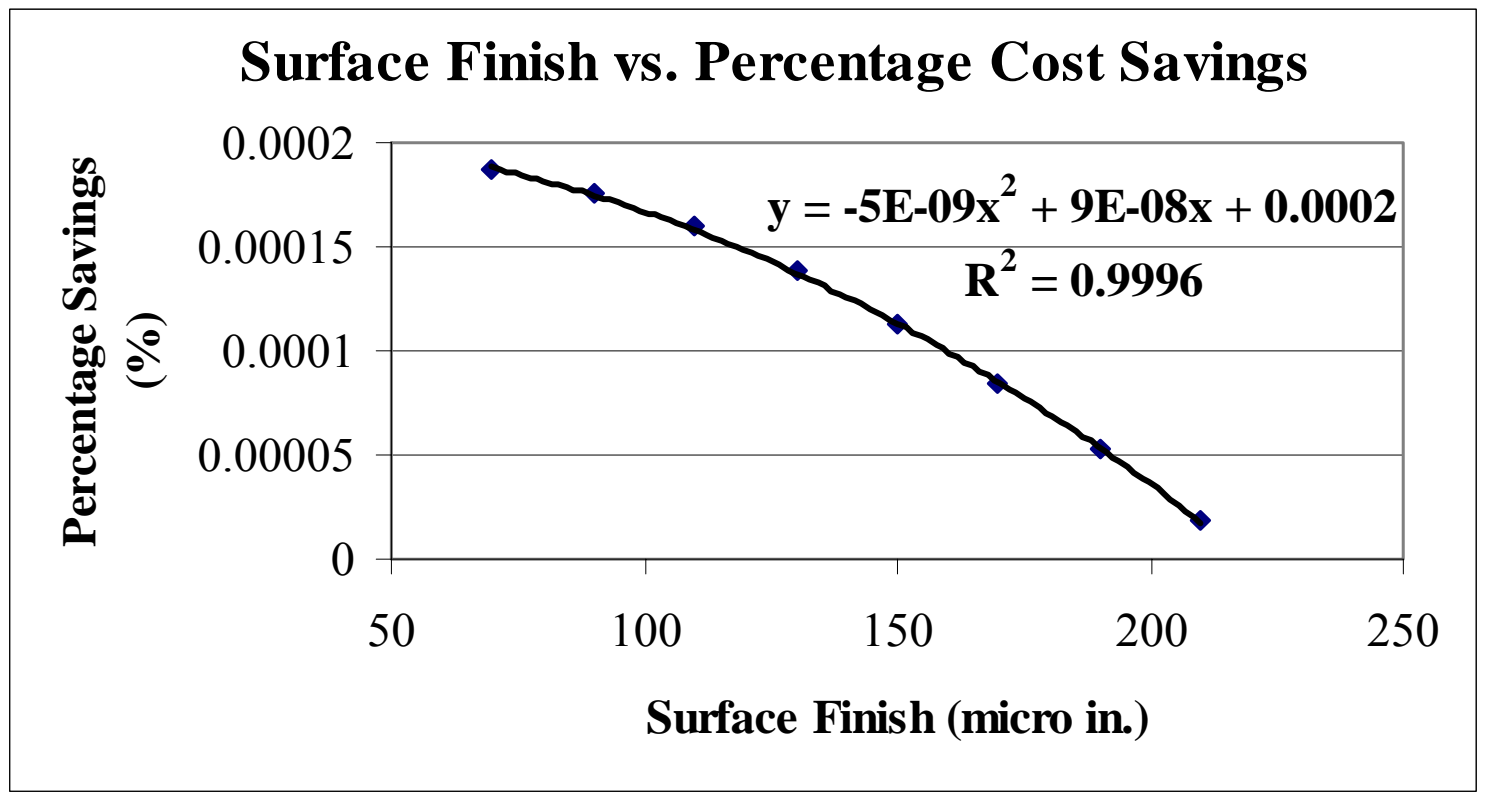

Figure 4.9: Effect of required surface finish on percentage cost savings 


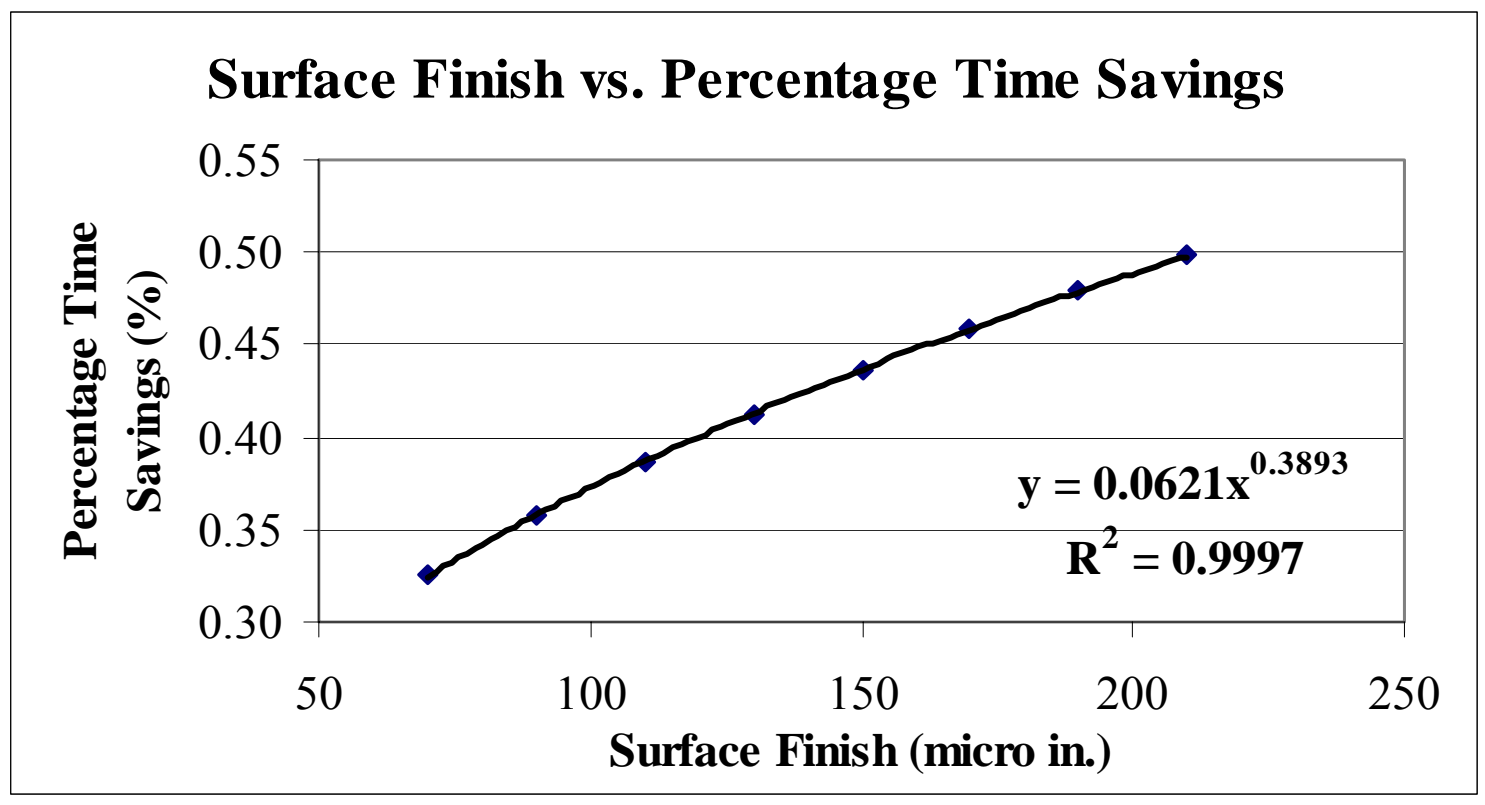

Figure 4.10: Effect of required surface finish on percentage time savings

The percentage cost savings decrease while the percentage time savings increase with increased relaxation in the surface finish requirement. It may be noted that for rough turning processes, the time savings are greater since the surface finish requirement is relaxed and the machining can be done at faster rate.

\subsubsection{Effect of Tool Cost/Edge}

For the sensitivity analysis with respect to the tool cost/edge, the value of tool cost is changed from $\$ 0.3$ to $\$ 1.2$ per edge in steps of $\$ 0.1$. The results from this analysis are shown in the following figures. It may be observed that the percentage time and cost savings decrease with an increase in the tool cost. This decrease can be attributed to the increased machining time because of reduce speed and feed values. 


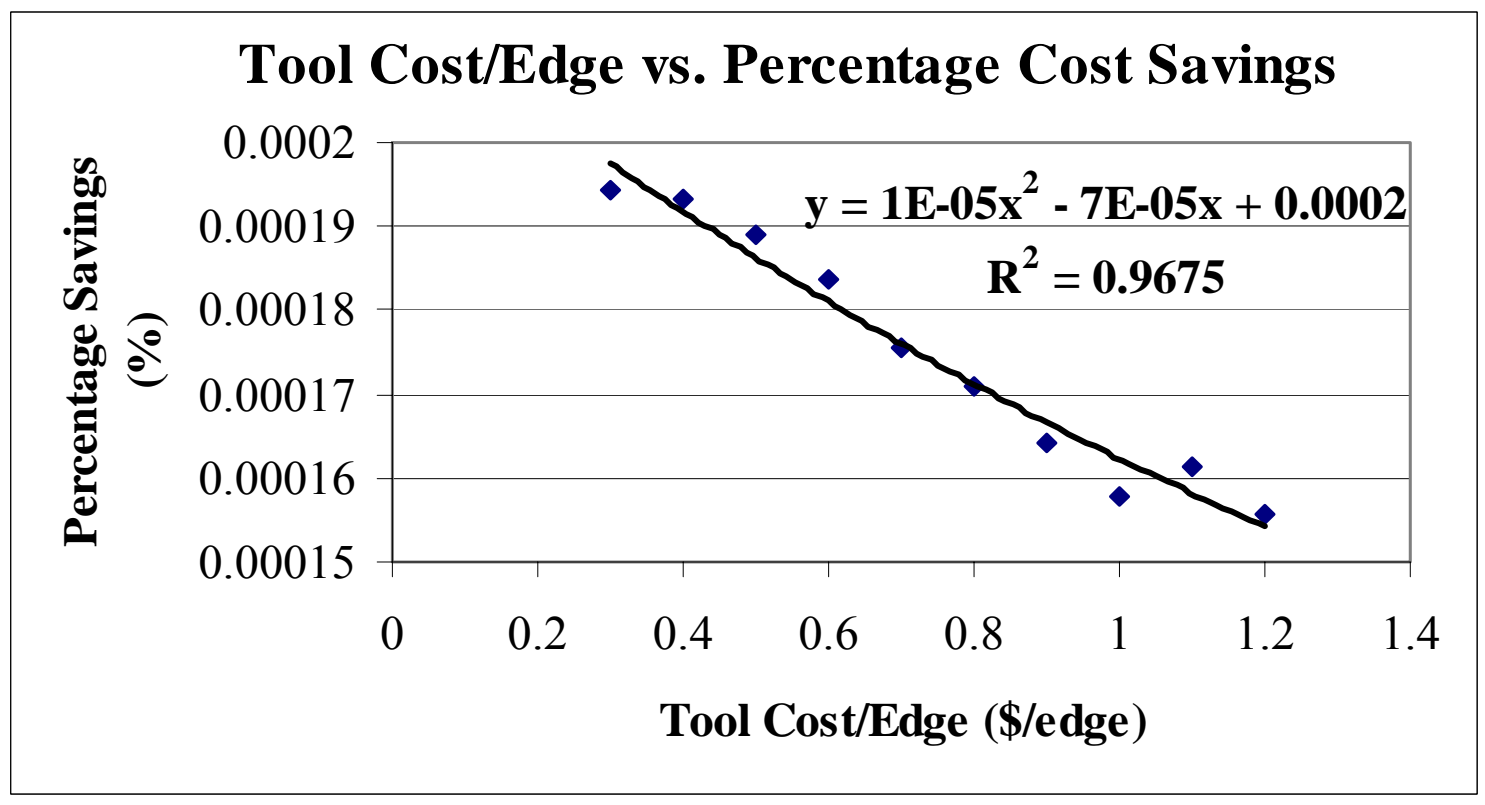

Figure 4.11: Effect of tool cost/edge on percentage cost savings

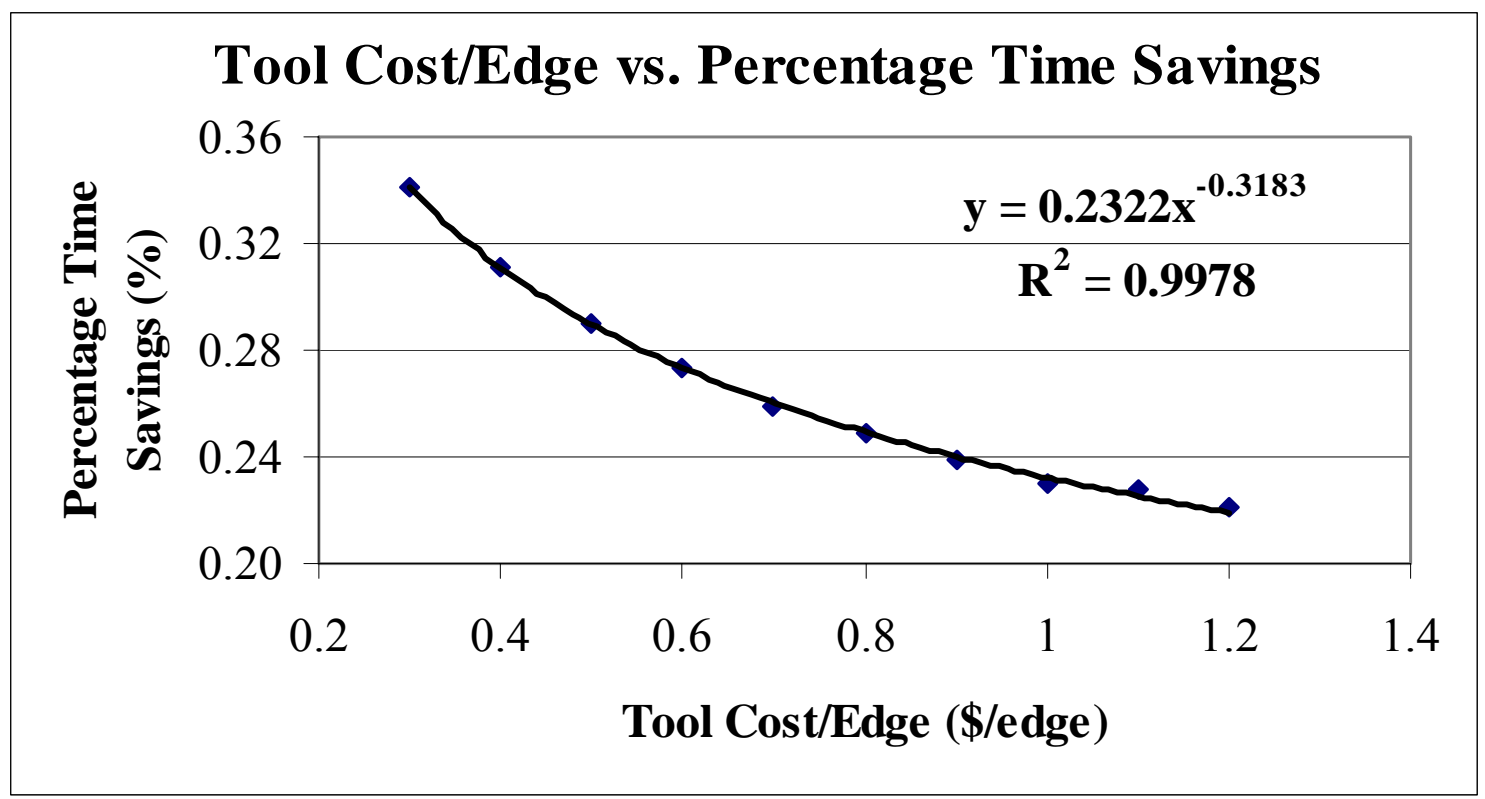

Figure 4.12: Effect of tool cost/edge on percentage time savings

\subsubsection{Effect of Simultaneous Change in Energy Usage Rate and Demand Rate}

For the sensitivity analysis with respect simultaneous change in the energy usage rate and the demand rate, the value of the energy usage rate is changed from $\$ 0.03 / \mathrm{kWh}$ to 
$\$ 1.1 / \mathrm{kWh}$ in steps of $\$ 0.02 / \mathrm{kWh}$ and demand rate is changed from $\$ 5 / \mathrm{kW}$ to $\$ 13 / \mathrm{kW}$ in steps of $\$ 2 / \mathrm{kW}$. The results from this analysis are shown in the following response surface plot.

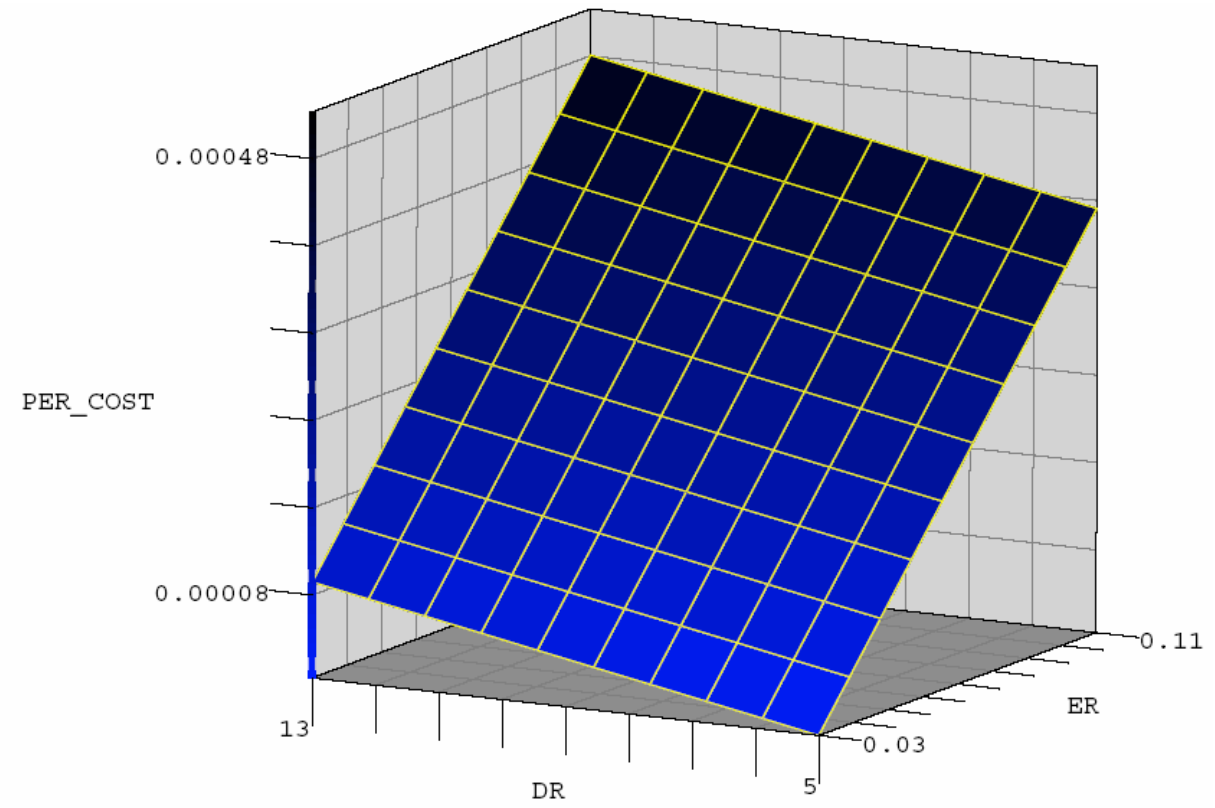

Figure 4.13: Effect of energy usage and demand rate on percentage cost savings

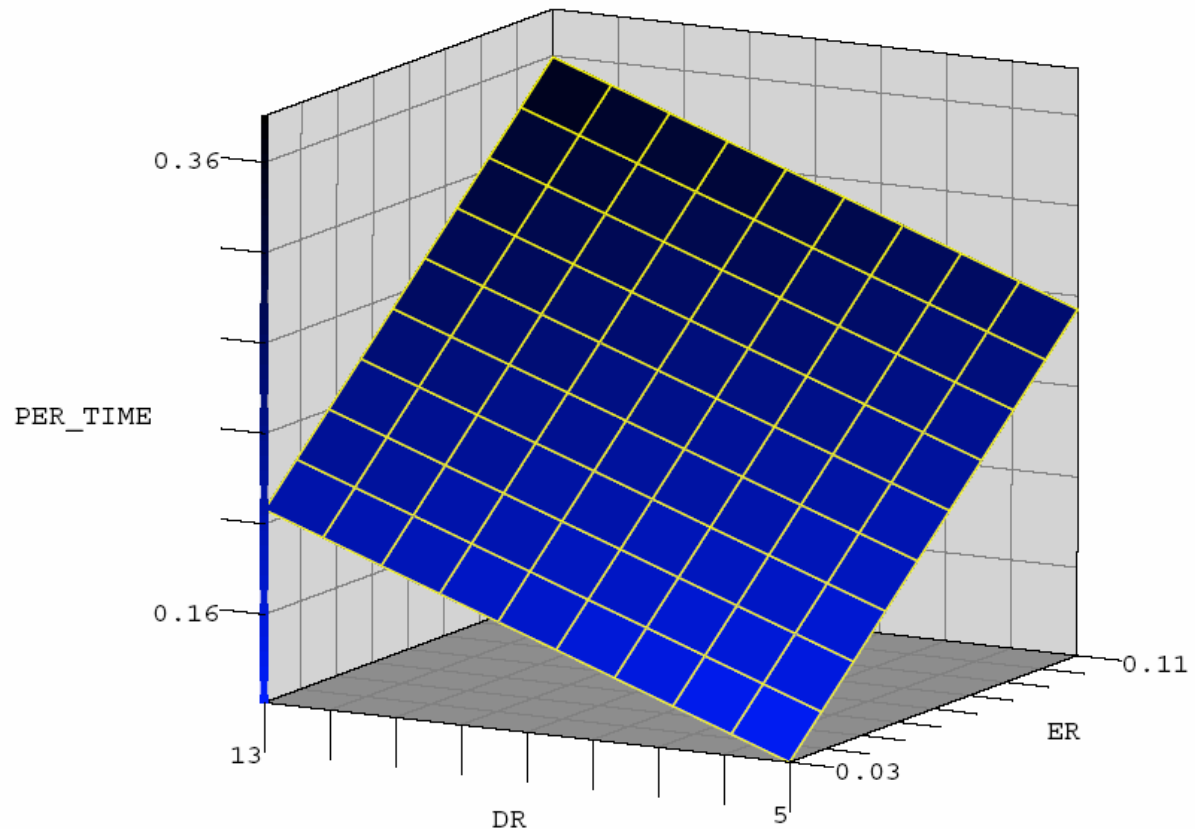

Figure 4.14: Effect of energy usage and demand rate on percentage time savings 
It can be seen that the percentage cost savings increase with increase in energy usage rate and the demand rate. Again, the cost savings are insignificant as compared to the current results. The effect of changes in the energy usage rate and the demand rate on the percentage time savings is illustrated by the response surface plot (Figure 4.14). Once again, increasing the demand rate and the energy usage rate results in increased percentage time savings. This should be noted since the proposed model not only reduces the cost but results into increased throughput for the system. Even though the cost savings are not significant, in many cases, the indirect savings from reduced machining time may be worth more than just machining cost savings.

\subsubsection{Effect of Simultaneous Change in Demand Rate and Labor Rate}

For the sensitivity analysis with respect to simultaneous change in the demand rate and the labor rate, the value of the demand rate is changed from $\$ 7 / \mathrm{kW}$ to $\$ 19 / \mathrm{kW}$ in steps of $\$ 3 / \mathrm{kW}$ and labor rate is changed from $\$ 0.1 /$ minute to $\$ 0.5 /$ minute in steps of $\$ 0.1 /$ minute. Since the cost savings are not significant, only the percentage time saving is illustrated in the following response surface plot.

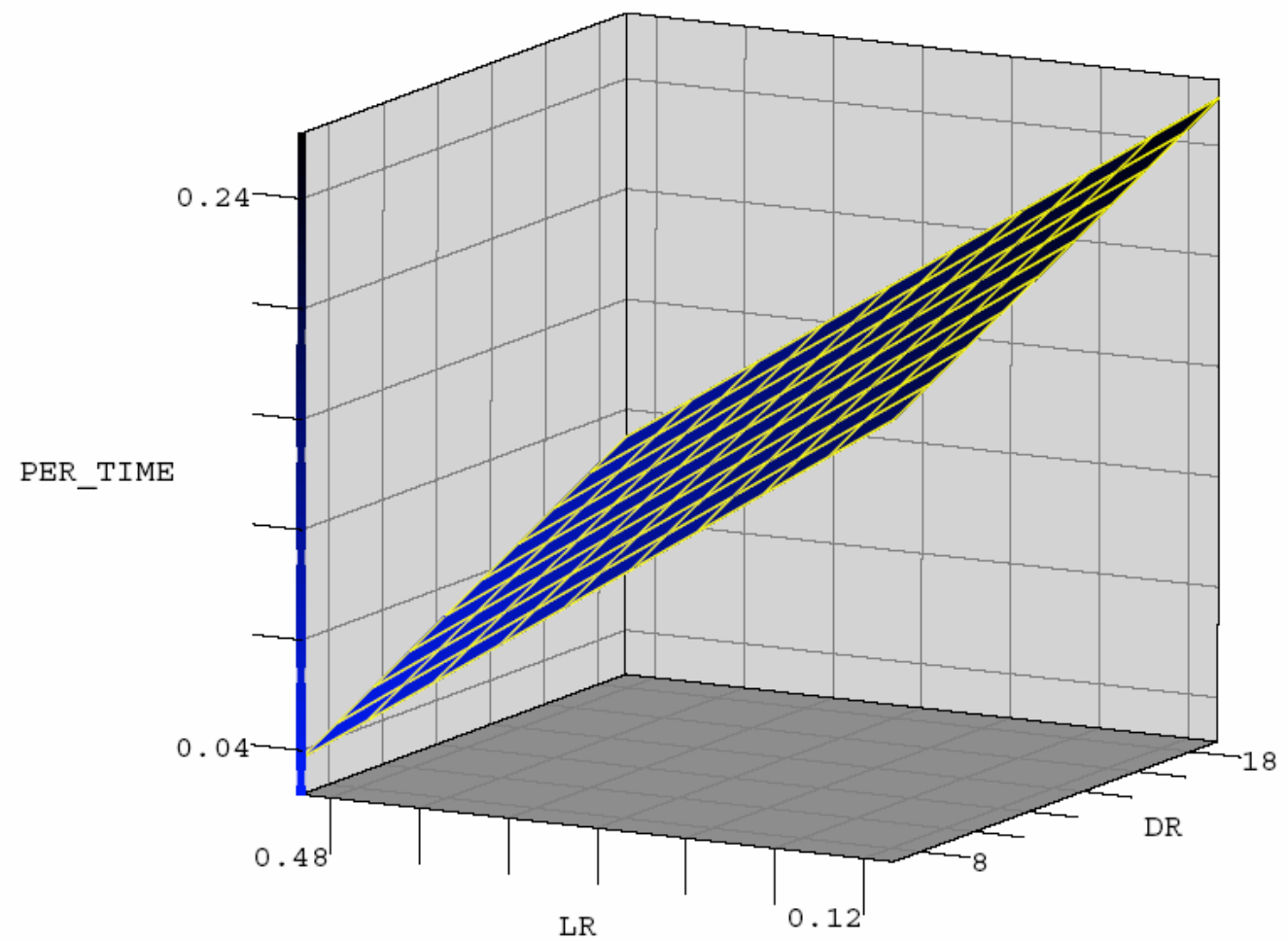

Figure 4.15: Effect of demand and labor rate on percentage time savings 
It can be seen that the percentage cost savings increase with increase in demand rate but reduces with increase in the labor rate. It is observed that the increasing the labor rate results into reduced machining time and therefore reduced total energy charges. The increase in the demand rate also results into reduced machining time and increased speed and feed but increases the total energy charges.

\subsubsection{Effect of Simultaneous Change in Energy Usage Rate and Labor Rate}

For the sensitivity analysis with respect simultaneous change in the energy usage rate and the labor rate, the value of the energy usage rate is changed from $\$ 0.05 / \mathrm{kWh}$ to $\$ 0.13 / \mathrm{kWh}$ in steps of $\$ 0.02 / \mathrm{kWh}$ and labor rate is changed from $\$ 0.1 /$ minute to $\$ 0.5 /$ minute in steps of $\$ 0.1 /$ minute. The results from this analysis are shown in the following response surface plot.

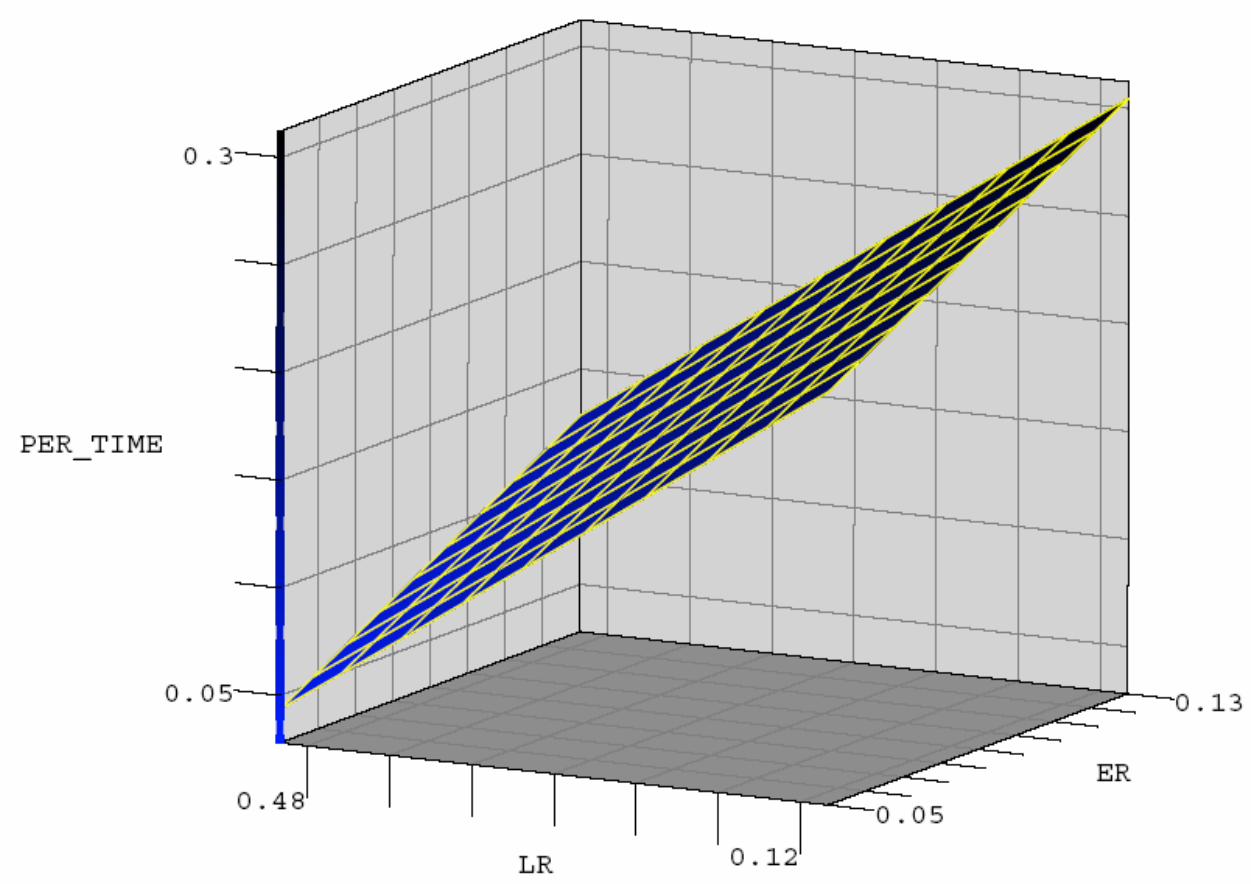

Figure 4.16: Effect of energy usage and labor rate on percentage time savings

It can been seen from the plot that increasing the labor rate results into reduced percentage time savings while increasing the energy usage rate does not result into significant increase in the cost savings. Therefore, the model will have higher effect in 
the case of low labor rate and high energy usage rate. This situation is possible with increasing automation in reducing energy supply resulting into increased energy cost.

\subsubsection{Effect on energy savings}

Based on the analysis performed in preceding sections, it is now clear that the proposed model optimizes the overall cost of the product. It is observed that the cost of energy is reduced by using the proposed model even in cases where the difference between the total cost using the current models and proposed models are not significant. Therefore, it may be concluded that the proposed model help save energy while maintaining at least the best machining cost. The effect of the energy usage rate and the demand rate on energy savings are shown in Figure 4.17 and 4.18. It may be observed that in both the cases, the energy cost savings increase with increase in the energy usage or demand rate. This savings is possible because the increase usage or demand rate result in reduced machining time and therefore reduced energy cost.

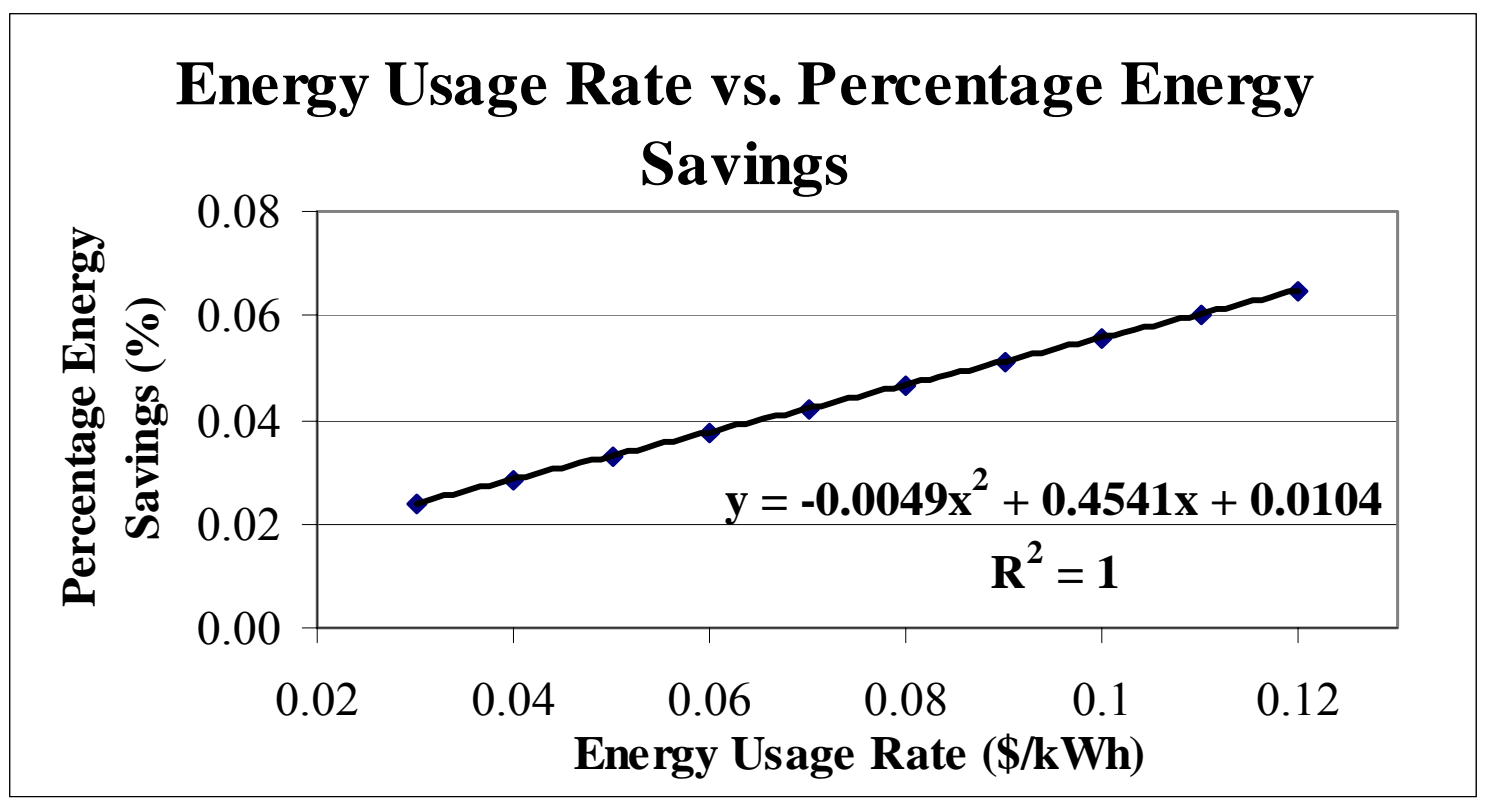

Figure 4.17: Effect of energy usage rate on percentage energy savings 


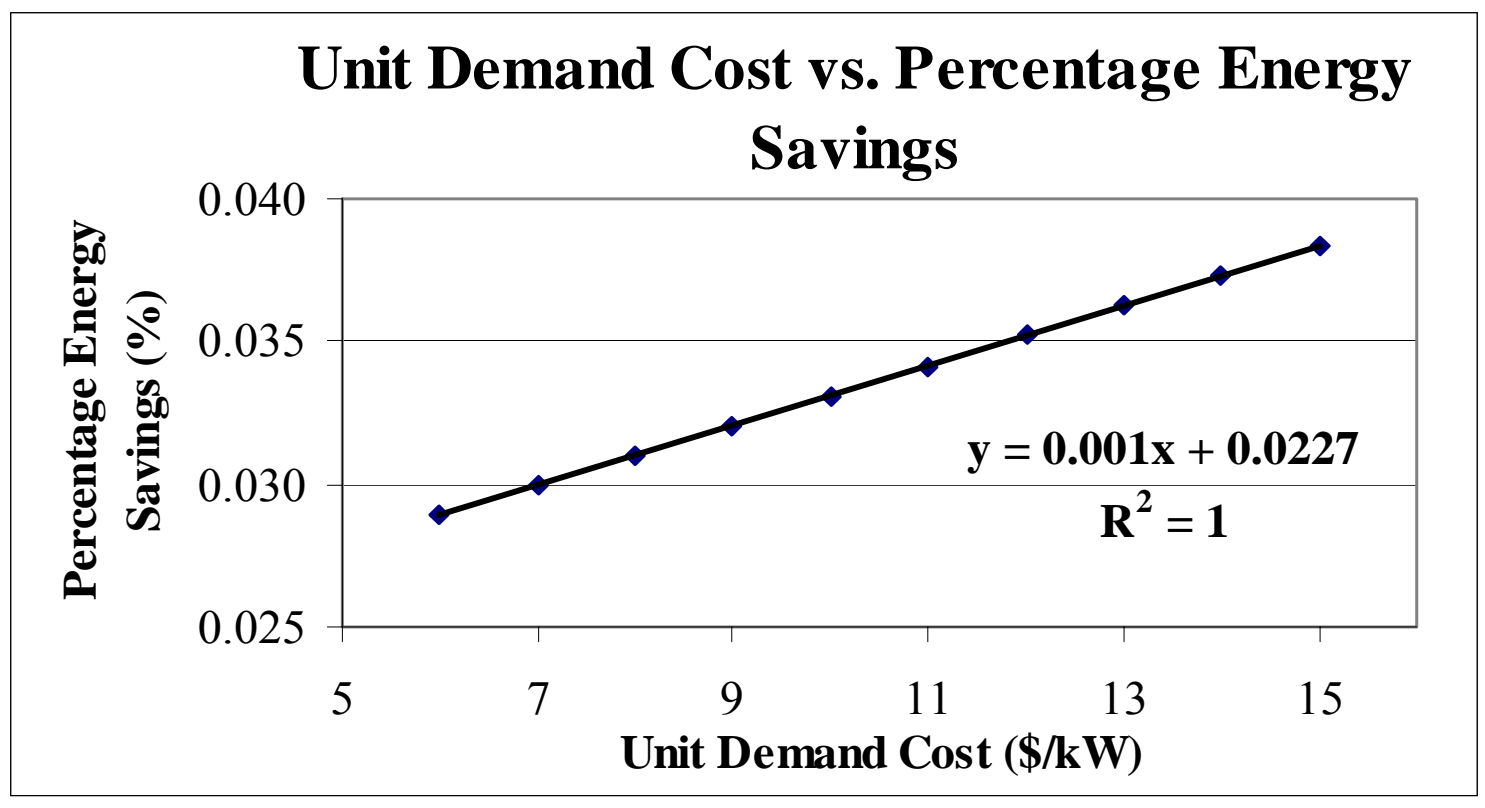

Figure 4.18: Effect of demand rate on percentage energy savings

\subsection{Limitation}

Based on the analysis performed during the sensitivity analysis, it was observed that the proposed model does not perform well for problems with horsepower binding constraint. Since the corresponding dual variable was set to zero, the proposed model does not consider this constraint while optimizing the machining parameters.

\subsection{Conclusion}

In this chapter, the proposed model was validated with existing models in the literature. An extensive sensitivity analysis was performed on different parameters in the model and the results were compared with the results obtained from one of the models proposed by Gopalakrishnan et al. [1991]. It was observed that the proposed model finds the optimum cost and results into productivity savings as well. It may be noted that the indirect savings from productivity increase may be much more significant than just the machining cost savings. Also, the increased productivity may result into increased capacity, which in turn may reduce the machining cost further by reducing the overall demand cost. 


\section{Chapter 5}

\section{Conclusion and Future Research Work}

\subsection{Conclusion}

From the analysis performed in Chapter 4, it may be concluded that the proposed model results into better machining parameter values which in turn results into reduced cost and increased productivity at the same time. It was noted that the percentage cost savings are not significant as compared to the results from the current literature. Also, the proposed model is more effective in cases where the labor rate is low and the energy prices (usage and demand rate) are high. This model can help the machinist in the areas with high energy prices to control the machining prices better than with the present machining economics models. Even though the results from the proposed model do not always result into significant savings, the model was able to find the better solution than that in the current literature in almost every case. One point that should be noted here is that the model does not consider the effect of horsepower constraint. Therefore, in cases where the solution is binding with respect to the horsepower constraint, the proposed model is not able to find the better solution.

\subsection{Future work}

The following points may be considered for future extension of this model.

1. The maximum power constraint may be considered with binding cases and some other method may be developed to solve the problem that has increased level of difficulty.

2. The tool life equation may be considered as a probabilistic model and may be incorporated in the process of optimizing the machining parameters.

3. The model may be modified to consider the effect of multi-pass turning operation. 
4. Different electrical billing options may be incorporated in the model to reflect the effect of changes in the energy rate patterns.

5. Depth of cut may be considered as a variable for optimizing the process parameters for multi-pass turning operation.

6. The model may be modified to consider other machining operations for optimizing the process parameters.

7. A general model may be developed using the same concept to consider a product line with more than one type of products.

8. Integrate the machining economics model with scheduling models to schedule the jobs on a machine in order to minimize the total cost of operations. 


\section{References}

Agapiou, J. S., 1992, The optimization of machining operations based on a combined criterion, part 1: The use of combined objectives in single-pass operations; part 2: Multi-pass operations. Transactions of the ASME, Journal of Engineering for Industry, 114, pp. 500-513.

Ahmad, N. and Haque, A.F.M.A., December 26-28, 2001, Optimization of process planning parameters for rotational components by genetic algorithms. $4^{\text {th }}$ International Conference on Mechanical Engineering, Dhaka, Bangladesh.

Al-Ahmari A. M. A., 2001, Mathematical model for determining machining parameters in multipass turning operations with constraints. International Journal of Production Research, Volume 39, Number 15, pp. 3367-3376.

Best Practices: Software Tools. (As on Oct 5, 2005)

http://www.eere.energy.gov/industry/bestpractices/software.html

Bhattacharyya, A., Faria-Gonzalez , R., and Ham, I., 1970, Regression analysis for predicting surface finish and its applications in the determination of optimum machining conditions. Transactions of the ASME, Journal of Engineering for Industry, 92, 711-714.

Boston, O. W., 1951, Metal processing. John Wiley and Sons, Inc., New York, NY.

Boston, O. W. and C. E. Kraus, 1932, Elements of milling. Transactions of the ASME, Vol. 54, RP-54-4, pp. 71-104.

Brierley R. and H. Siekmann, 1964, Machining principles and cost control. McGraw-Hill Book Co.

Buffington and Wolf, 2005, Deregulation of electricity generation in Pennsylvania. (As on Nov. 22, 2005) http://www.age.psu.edu/extension/factsheets/h/H77.pdf

Chen, M.C. and Tsai, D.M., 1996, A simulated annealing approach for optimization of multi-pass turning operation. International Journal of Production Research, Vol. 34, No. 10, 2803-2825. 
Cook, N. H., 1966, Manufacturing analysis. Addison-Wesley Publishing Company, Inc., pp. $36-39$.

Creese, R.C., 1979, A primal-dual solution procedure for geometric programming. ASME Technical Paper, Paper No. 79-DET-78.

Dautzenberg, J.H., Veenstra, P.C. and Van der Wolf, A.C.H., 1981, The minimum energy principle for the cutting process in theory and experiment. Annals of CIRP, Vol. 30, pp. $1-4$.

Duffin, R.J., Peterson, E.L. and Zener, C., 1967, Geometric programming - theory and applications. John Wiley \& Sons, Inc., New York.

EC\&M: Planning to beat the high cost of electrical power, February 1, 1998. EC\&M magazine. (As on October 05, 2005)

http://ceenews.com/mag/electric_planning_beat_high/index.html

EC\&M: NEMA starts motor-efficiency program, Jul 1, 2001. EC\&M magazine. (As on Oct 05, 2005) http://ceenews.com/mag/electric_nema_starts_motorefficiency/

Energy Information Administration (EIA), August 15, 2005, Annual energy review long-term historical statistics all in one place, Report No. DOE/EIA-0384 (2004).

Ermer, D.S. and Kromordihardjo, S., 1981, Optimization of multipass turning with constraints. Journal of Engineering for Industry, Transactions of the ASME, 103, 462-468.

Executive Order 13123 - Greening the government through efficient energy management, June 8, 1999. (As on Oct 5, 2005)

http://www.eere.energy.gov/femp/pdfs/eo13123.pdf

Gilbert, W.W., 1950, Economics of machining - theory and practice. Cleveland, OH American Society of Metals.

Gopalakrishnan, B. and Al-Khayyal, F., 1991, Machining parameter selection for turning with constraints: an analytical approach based on geometric programming. International Journal of Production Research, Vol. 29, No. 9, 1897-1908. 
Gupta, R., Batra, J. and Lal, G., 1995, Determination of optimal subdivisions of depth of cut in multipass turning with constraints. International Journal of Production Research, 33, 2555-2565.

Hitomi, K., 1991, Analysis of optimal machining conditions for flow-type automated manufacturing systems. International Journal of Production Research, Vol. 29, No. $12,2423-2432$.

Hitomi, K., 1996, Manufacturing systems engineering: a unified approach to manufacturing technology, production management, and industrial economics. $2^{\text {nd }}$ edition, pp 155. Taylor \& Francis, London.

Industrial Rates, Utilities in greater Cleveland. (As on Nov. 22, 2005) http://www.cose.org/pdf/FactSheets/Utilities.pdf

Koulamas, C.P., 1991, Simultaneous determination of optimal machining conditions and tool replacement policies in constrained machining economics problems by geometric programming. International Journal of Production Research, Vol. 29, No. $12,2407-2421$.

Kronenberg, M., 1940, Machining with single point tools. IQQ1 Engineer, Vol. 8, Nos. 9 and 10, pp. $17-19$ and $46-48$.

Lee, B.Y. and Tarng, Y.S., 2000, Cutting-parameter selection for maximizing production rate or minimizing production cost in multistage turning operation. Journal of material processing Technology, 105, 61-66.

Liang, M., Mgwatu, M. and Zuo M., 2001, Integration of cutting parameter selection and tool adjustment decision for multipass turning. International Journal of Advance Manufacturing Technology, 17, 861-869.

Machining Data Handbook, $3^{\text {rd }}$ edition, Vol. 1 \& 2, 1980. Metcut Research Associates Inc., Cincinnati, Ohio.

Mate, A., 2002, Energy analysis and diagnostics in wood manufacturing industry. Master's Thesis, West Virginia University. 
Merchant, M. E., 1944, Basic mechanics of the metal cutting process. Journal of Applied Mechanics, Vol. 66, 1944, A168-A175.

Merchant, M.E., 1974, Industry-research integration in computer aided manufacturing. International Conference Prod. Tech., Melbourne, Australia.

MSN Money: Company Reports. (As on Oct 05, 2005) http://moneycentral.msn.com/

Nadel, S., Elliott, R.N., Shepard, M., Greenberg, S., Katz, G. and Almeida, A.T.DE, 2002. Energy efficient motor systems: a handbook on technology, program, and policy opportunities, 2nd edition. American Council for an Energy-Efficient Economy, Washington, D.C.

National Research Council (NRC), Unit Manufacturing Processes: Issues and Opportunities in Research, 1995. The National Academies Press, Washington, DC.

Prasad, A.V.S.R.K., Rao, P.N. and Rao, U.R.K., 1997, Optimal selection of process parameters for turning operations in a CAPP system. International Journal of Production Research, Vol. 35, No. 6, 1495-1522.

Saravanan, R., Asokan, P. and Vijayakumar, K., 2003, Machining parameter optimisation for turning cylindrical stock into a continuous finished profile using genetic algorithm (GA) and simulated annealing (SA). International Journal of Advance Manufacturing Technology, 21, 1-9.

Schedule 20, General service. West Penn Power Company. (As on Nov. 22, 2005)

http://energy.opp.psu.edu/engy/ElecUtil/ElecRate/APS/PA20.pdf

Schedule "B", General service. Monongahela Power Company. (As on Nov. 22, 2005)

http://www.alleghenypower.com/Tariffs/WV/Wvmontariffs/WVMPRetailTariff.pdf

Schedule "C", General and commercial service. Allegheny Power. (As on Nov. 22, 2005)

http://www.alleghenypower.com/Tariffs/MD/Mdc.pdf

Schedule "K", General power service rate. Monongahela Power Company. (As on Nov. $22,2005)$

http://www.alleghenypower.com/Tariffs/WV/Wvmontariffs/WVMPRetailTariff.pdf 
Schedule LGS, Large general service. Monongahela Power Company. (As on Nov. 22, 2005) http://www.alleghenypower.com/Tariffs/WV/Wvmontariffs/WVMPlgs.pdf

Shaw, M. C., N. H. Cook, and A. P. Smith, 1952, The mechanics of three dimensional cutting operations. ASME Transactions, Vol. 74, pp. 1055 - 1064.

Shin, Y.C. and Joo, Y.S., 1992, Optimization of machining conditions with practical constraints. International Journal of Production Research, vol. 30, No. 12, 29072919.

Tan, F.P. and Creese, R.C., 1995, A generalized multi-pass machining model for machining parameter selection in turning. International Journal of Production Research, vol. 33, No. 5, 1467-1487.

Taylor, F.W., 1907, On the art of cutting metals. Transaction of American society of Mechanical Engineers, vol. 28, pp. 70-350.

Tsai, P., 1986, An optimization algorithm and economic analysis for a constrained machining model. Ph.D. Dissertation, West Virginia University.

Wang, J., Kuriyagawa, T., Wei, X.P. and Guo, D.M., 2002, Optimization of cutting conditions for single pass turning operation using a deterministic approach. International Journal of Machine Tools \& Manufacture, 42, 1023-1033.

Will, C.F., 4-6 May 1993, Factors that affect your plant power bill. Textile, Fiber and Film Industry Technical Conference, IEEE 1993 Annual, page 10/1-10/4. 